Journal of Universal Language 15-1

March 2014, 1-70

\title{
Mandarin Bare Classifier-Nouns: Towards a Universal Structure for Classifiers and Plurals*
}

\author{
Hsiang-Hua Chang \\ Oakland University, USA
}

\begin{abstract}
Mandarin, as other classifier languages, usually requires a classifier when numerals, quantifiers, or demonstratives are present, but also allows bare classifier-nouns (CL-N) without any determiners. This paper examines two empirical questions: (i) What is the structure of CL-N that can account for its behavior? (ii) Under what conditions are bare CL-Ns acceptable? Following Borer's Exo-Skeletal framework, I draw a parallel between Mandarin classifiers and the English plural. Mandarin ben shu 'CL book' and English books both are CLASSIFIER PHRASES carrying no quantity information. Numeral-classifier-nouns (Num-CL-Ns), such as san ben shu 'three books,' are QUANTITY
\end{abstract}

\footnotetext{
* I am very grateful to my doctoral advisor, Prof. Cristina Schmitt, for comments and discussions on earlier versions of this paper. I thank the anonymous reviewers and the managing editor for comments. Any remaining mistakes are solely mine.

Hsiang-Hua Chang

Department of Modern Languages and Literatures, Oakland University

Rochester, Michigan 48309, United States of America

Phone: 12483704248; Email: chang23@oakland.edu
}

Received February 11, 2014; Revised March 10, 2014; Accepted March 15, 2014. 
2 Mandarin Bare Classifier-Nouns: Towards a Universal Structure for

PHRASES carrying quantity information. This proposal correctly predicts that CL-Ns and Num-CL-Ns have different distributions due to different structures. Supporting data are drawn from CL-Ns in argument and non-argument positions in various constructions to attest the prediction that when the quantity information is needed in the discourse, Num-CL-Ns will be obligatory; in contrast, when the quantity information is not crucial, CL-Ns will be preferred or obligatory.

Keywords: Mandarin, classifier, noun phrase, quantity, telicity, (non-)argument

\section{Introduction}

Mandarin lacks plural inflections and allows bare nouns such as mao 'cat' to be arguments, as shown in (1). When a numeral or a quantifier is present in Mandarin, a classifier is needed to construct a grammatical phrase, as in (2a). In contrast, English is not a classifier language and a countable noun needs a plural marker $-s$ when a numeral appears, as shown in $(2 b) .{ }^{1}$

(1) Mao xihuan chi
cat like
'The cat likes to eat ice cream.'

${ }^{1}$ Labels used in this paper: C-complement, CL-classifier, ClP-classifier phrase, D-determiner, DE-adjectival or adverbial marker, DP-determiner phrase, FUTfuture tense marker in Romance language examples, GUO-experiential aspect marker -guo, LE-perfective aspect marker -le, N-noun, NP-noun phrase, Numnumeral, NumP-numeral phrase, PL-plural marker, QP-question particle, SFPsentence final particle, V-verb, VP-verb phrase, XIE-xie as in yixie 'some,' ZAI-progressive aspect marker $z a i$, \#P-quantity phrase. If the English gloss for a Mandarin word is a compound, a colon is used to save space, e.g., gege 'elder:brother.' These labels mainly adopt the well-known custom in $\mathrm{Li} \&$ Thompson (1981). 


$\begin{array}{lll}\text { (2) a. } & \text { san } \\ \text { three } & \text { CL } \\ \text { 'three cats' } & \text { mao }\end{array}$

b. three cats

In addition to the bare noun $(\mathrm{N})$ and numeral-classifier-noun (Num-CL-N) structure, Mandarin also allows CL-N construction without any numbers or determiners as in (3) (Lü 1955, 1980; Hu 1958; Chao 1968; Cheng \& Sybesma 1999, 2005; Yang 2001).
$\begin{array}{lllll}\text { (3) Wo zuotian } & \text { mai-le } & \text { zhi } & \text { mao. } \\ \text { I } & \text { yesterday } & \text { buy-LE } & \text { CL } & \text { cat }\end{array}$ 'Yesterday I bought a cat.'

Many researchers assume Mandarin CL-N to be $y i-C L-N$ with an omitted $y i$ 'one' (Lü 1955, 1980; Hu 1958; Chao 1968; Yang 2001). However, this assumption cannot explain all the distribution of CL-Ns. As observed by Cheng \& Sybesma (1999), CL-N and $y i$-CL-N have a different distribution. Yi-CL-N cannot always be abbreviated to CL-N. They further argue that the distinct distributions of CL-N and $y i-C L-N$ is due to their distinct specificity. Telic predicates require specific arguments, such as $y i$-CL-N, but disallow CL-N, which is non-specific. Nevertheless, people may defend the hypothesis of $y i$ 'one' omission by claiming that $y i$ 'one' in $y i$-CL-N sometimes can be omitted but sometimes cannot. In other words, CL-N is a subset of $y i-\mathrm{CL}-\mathrm{N}$, and the place where $y i-\mathrm{CL}-\mathrm{N}$ cannot be reduced to CL-N is the environment that requires specific nouns.

This paper will examine CL-N constructions. I will provide evidence, especially the cases where CL-N is permitted but $y i-\mathrm{CL}-\mathrm{N}$ is not, to show that integrating the hypothesis of $y i$ 'one' omission and the specificity account together still cannot explain 
4 Mandarin Bare Classifier-Nouns: Towards a Universal Structure for

all the CL-N phenomena. Given that $y i-C L-N$ and CL-N have a distinct distribution, the main objective of this paper is to propose a structure for CL-N to account for its behavior. I will support this proposal by investigating the following two questions: (i) how does CL-N compare to Num-CL-N in Mandarin - what are the obligatory cases for CL-N and Num-CL-N respectively; (ii) what is the interaction between aspect and different nominal structures - what is the distinct environment that allows CL-N, Num-CL-N, and bare $\mathrm{N}$ respectively.

Cheng \& Sybesma (1999), based on an analysis of the cases where the target noun phrases are argumental, argue that the lack of telic reading of CL-Ns comes from the fact that they are not specific. I assume that it is the lack of quantity structure that makes CL-Ns only be allowed with atelic predicates, not the lack of specificity. Namely, I will assume that the lack of specificity of CL-Ns comes from their lack of quantity. This will account not only for the argumental cases, but also for the non-argumental cases.

Most of the previous studies have focused on the CL-Ns in argumental positions, while the CL-Ns in non-argumental positions have been ignored, except for Lü (1980), Yang (2001), and Biq (2002). This paper examines the distribution of Mandarin CL-Ns in argumental and non-argumental positions and proposes an analysis which will be applicable to various constructions. The evidence from non-argumental CL-Ns will show that CL-Ns do not only appear in immediate post-verbal positions, as is claimed by previous studies ( Hu 1958, Chao 1968, Lü 1980, and Yang 2001).

As noted in (2), English uses plural morphology, while Mandarin uses classifiers. Borer (2005a) explains this language variation of plural markers and classifiers from the perspective of the functional structure. To account for the apparent complementary distribution of plural and classifier morphology across languages, Borer argues that these are two possible 
morphological realizations of a classifier head. Both plural morphology and classifiers divide mass-like elements into countable elements.

After comparing other accounts for CL-Ns, I adopt Borer's Exo-Skeletal framework $(2005 \mathrm{a}, \mathrm{b})$ in my analysis. I will argue that Mandarin CL, as English plural $-s$, heads the classifier phrase (ClP). ${ }^{2}$ A ClP projection is like a counter or divider. The ClP projection makes nominals 'countable' but not 'counted.' ClP provides no quantity information, which makes it unable to contribute to the telic interpretation. Consequently, argumental CL-Ns following an atelic verb appearing in a sentence without any aspectual markers will give us atelic readings since the structure of CL-N is similar to English bare plurals, as illustrated in (4). CL-Ns may also appear in predicate (non-argument) positions, where telicity is irrelevant, as zhi chu 'CL pig' in (5).

$\begin{array}{lll}\text { (4) } & \text { xie } \quad \text { feng } & \text { xin } \\ \text { write } \quad \text { CL } & \text { letter } \\ \text { 'write letters' } & \end{array}$

$\begin{array}{lllll}\text { (5) Wo } & \text { liang-ge } & \text { meimei } & \text { changchang } \\ \text { I } & \text { two-CL } & \text { younger:sister } & \text { usually } & \\ \text { shui } & \text { de } & \text { xiang } & \text { zhi } & \text { zhu. } \\ \text { sleep } & \text { DE } & \text { like } & \text { CL } & \text { pig } \\ \text { 'My two younger } & \text { sisters usually sleep } & \text { as sound as pigs.' }\end{array}$

Although CL-Ns and English bare plurals have a different distribution, I argue that they behave similarly in their (i) inability to contribute to the telic interpretation of the verb phrase (VP), (ii)

2 Whether classifiers project a functional category varies among different approaches. (See Tang 1990, Gao 1994, Cheng \& Sybesma 1999, Yang 2001, and Borer 2005). This paper will focus mainly on the studies which bring up the issue of bare CL-Ns. 
6 Mandarin Bare Classifier-Nouns: Towards a Universal Structure for

lack of specific readings, and (iii) ability to appear in non-argument positions.

The organization of this paper is as follows. Section 2 will discuss previous analyses of CL-Ns in Mandarin, followed by a new proposal based on Borer $(2005 \mathrm{a}, \mathrm{b})$ in section 3. The data supporting my proposal, the distribution of Num-CL-N and CL-N and the interaction between aspect and (Num)-CL-N, will be discussed in section 4 and 5 . The last section concludes the paper.

\section{Previous Analyses of Classifier-Noun in Mandarin}

Previous analyses of CL-Ns mainly discussed CL-Ns in argumental positions. Chao (1968) observes that $y i$-CL-Ns can be phonologically reduced to CL-Ns. Cheng \& Sybesma (1999) discover that CL-Ns are prohibited in telic sentences and they argue that the lack of telic reading of CL-Ns comes from them not being specific. ${ }^{3}$ Borer (2005a) assumes the singular 'one' interpretation for Mandarin CL-Ns and proposes that Mandarin classifiers head the fused Quantity/counting and CL phrases (\#/ClP) because they simultaneously convey the meaning 'one,' which projects $\# \mathrm{P}$, and also provide the dividing function, as any element projecting a ClP does.

Studies, such as Lü (1980) and Biq (2002), that mention CL-Ns in non-argumental positions, did not provide a structural analysis. Lü only describes the data without any analysis and Biq provides a semantic/pragmatic analysis. I will focus on the analyses with a syntactic perspective and inevitably I will not be able to get into details the phonological (Chao 1968) and pragmatic (Li 2000a, b; Biq 2002) analyses.

3 To be consistent, this paper will use the term "telic" instead of "bounded," which is used in Cheng \& Sybesma. 


\subsection{The Phonological Reduction Analysis}

It is generally assumed that CL-N is the phonological reduction of $y i$-CL-N (Chao 1968). Therefore, (6b) is phonologically reduced from $(6 a)$.
(6)
a. Wo he-le yi-bei cha.
I drink-LE one-cup tea
'I drank one cup of tea.'
b. Wo he-le bei cha
I drink-LE cup tea
'I drank a cup of tea.'

Phonological reduction cannot explain why in the following construction, $y i-\mathrm{CL}-\mathrm{N}$ cannot be reduced to CL-N, as noted by Cheng \& Sybesma (1999, 2003). For example, 'one-cup tea' in (7a) cannot be reduced to (7b) 'cup tea.'

$\begin{array}{llll}\text { (7) a. Wo } & \text { he-wan-le } & \text { yi-bei } & \text { cha. } \\ \text { I } & \text { drink-finish-LE } & \text { one-cup } & \text { tea } \\ \text { 'I drank up one cup of tea.' } & \\ \text { b. *Wo } & \text { he-wan-le } & \text { bei } & \text { cha. } \\ \text { I } & \text { drink-finish-LE } & \text { cup } & \text { tea } \\ \text { 'I drank up a cup of tea.' } & \end{array}$

\subsection{The Covert Numeral Analysis or Cliticization}

Yang (2001) provides two different proposals to account for the occurrences of CL-Ns but she does not suggest which better explains the data. One of her suggestions argues that Num-CL is a complex head, in which CL is a suffix to Num (p. 58). A 
8 Mandarin Bare Classifier-Nouns: Towards a Universal Structure for

classifier cannot be separated from a numeral; thus, there must be a covert $y i$ 'one' in CL-N. Her other proposal claims that the CL in CL-N sequence is a clitic (pp. 72-75). CL is cliticized to the verb and shows dependency on the following $\mathrm{N}-$ the clitic classifier cannot occur without the following $\mathrm{N}$.

The problem for both phonological reduction and covert numeral analyses is that they cannot explain examples such as (7) above, in which $y i$-CL-N cannot be reduced to CL-N. And the cliticization analysis may have problems explaining the cases where an aspect marker appears between the verb and the CL, as shown in (8).

(8) Mama zuotian mai-le ba san. mom yesterday buy-LE CL umbrella 'Mom bought an umbrella yesterday.'

\subsection{The NumeralP and Specificity Analysis}

Cheng \& Sybesma (1999) observe the distributional difference in (7) and argue that CL-N is not the reduction of $y i$-CL-N. They (1999: 539) propose that according to the different semantics of the CL-Ns, i.e., the (in)definiteness, CL-Ns will have different syntax: Mandarin and Cantonese indefinite CL-Ns are NumeralPs, as shown in (9a), while Cantonese definite CL-Ns are ClP, as shown in (9b). Mandarin CL-Ns can only be indefinite; therefore, for them, Mandarin (Num)-CL-N is always a NumeralP and 'the Numeral can be overt or nonovert' (p. 530). 
(9) a. Indefinite CL-Ns

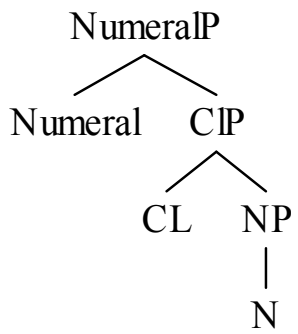

b. Definite CL-Ns

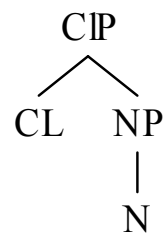

The claim that Mandarin Num-CL-N and CL-N are always indefinite and thus should be NumeralPs and have a projection like (9a) cannot account for the different distribution of Num-CL-N and CL-N. Therefore, they further propose the specificity analysis to account for the distributional difference. They propose that the distinct distribution is due to the semantics of the noun phrase and the clause. Mandarin Num-CL-Ns can be interpreted as specific or non-specific while CL-Ns can only be non-specific. Based on the evidence that telic predicates, such as drink-finish-LE 'drank up' in (7), do not allow CL-Ns, they argue that telic predicates only co-occur with specific nouns; therefore, CL-Ns are non-specific. Another piece of evidence they provide is the $b a$-construction, which also offers a telic context, as shown in (10). ${ }^{4}$ The same pattern is found in $b a$-construction: Num-CL-N is acceptable, while CL-N is not.

4 Lü (1955) mentions some cases where Mandarin CL-N is allowed in $b a$-construction. This case is not a contradiction to Cheng \& Sybesma's observation that $b a$-construction only allows specific nouns since only the general classifier ' $g e$ ' is permitted in this case and the ge-N 'CL-N' in this construction can only be interpreted as definite. As Lü suggests, in this construction, ' $g e$ ' is a definite marker and $g e-\mathrm{N}$ is a definite nominal. 
10 Mandarin Bare Classifier-Nouns: Towards a Universal Structure for

(10) a. Ta ba yi-bei cha he-wan-le.

he BA one-cup tea drink-finish-LE/SFP

'He drank up one cup of tea.'

b. *Ta ba bei cha he-wan-le.

he BA cup tea drink-finish-LE/SFP

'He drank up a cup of tea.'

However, the reason why telic predicates must license specific nouns is not clear. The following Mandarin example (11a) shows that a telic event does not necessarily grant specific objects. The predicate in (11a), jian-hao 'build up,' is a creation verb; thus the objects are not presupposed and 'three ships' need not to be specific.

a. Lisi qunian jian-hao-le san-sao chuan, Lisi last:year build-good-LE three-CL ship, keshi wo bu zhidao shi na san-sao. but I not know be which three-CL 'Last year Lisi built up three ships but I don't know which three.'

b. *Lisi qunian jian-hao-le sao chuan. Lisi last:year build-good-LE CL ship

Comparing the grammatical (11a) and the unacceptable (11b), I notice that telic predicates license a phrase with quantity and disallow a phrase without quantity information.

Contrary to Cheng \& Sybesma's argument, telic events allow both specific nominals (7) and (10) and non-specific nominals (11). Why CL-Ns are barred in telic sentences must follow from something else and not because CL-Ns are non-specific. Since Num-CL-Ns can be both specific and non-specific, what may be 
concluded from (7), (10), and (11) is that telic predicates require quantity, but not necessarily specificity. Quantity contributes to telicity, and non-quantity cannot contribute to telicity so non-quantity cannot appear in telic predicates.

It seems that it is the lack of quantity structure that makes CL-Ns disallowed with telic predicates, not the lack of specificity. If Cheng \& Sybesma are correct that CL-Ns can only be interpreted as non-specific, I argue that this lack of specificity comes from the lack of quantity.

\subsection{Mandarin Classifier-Noun as \#/CLP}

Unlike Endo-Skeletal approaches, which construct the syntax around the lexical items with well-defined properties that project particular structures, Borer (2005a) proposes the Exo-Skeletal approach which reduces the redundancies in the grammar by shifting many of the traditional formal properties of the lexicon, such as the mass/count distinction, to syntactic and morphological properties of a language. In the Exo-Skeletal approach, a listeme is simply a sound-meaning pair, 'the computation emerges from properties of structure, rather than properties of listemes,' and 'the burden of the computation is shouldered by the properties of . . . functional vocabulary . . . and functional structure' (2005a: 21). She proposes to view functional heads as open values, $<\mathrm{e}>$, which are assigned range by a variety of means, such as functional formatives the, a, will, head features <past tense>, or operators GEN (generic operator). Two types of functional projections that concern us most in this paper are Classifier Phrase (ClP) in (12) and Quantity Phrase (\#P) in (13). (The ClP may not necessarily project in the \#P structure as we will see later). For example, cats is a ClP in English, in which the plural morpheme is a head feature realized as $-s$ that assigns range to the open value $\langle\mathrm{e}\rangle_{\text {DIVISION }}$ and heads the ClP. A \#P head, $\langle\mathrm{e}\rangle_{\#}$, is assigned range by numerals, quantifiers, and definite and indefinite articles. 
12 Mandarin Bare Classifier-Nouns: Towards a Universal Structure for

Examples such as five books, some water, the cake, a dog have \#P projections. ${ }^{5}$

$(12)$

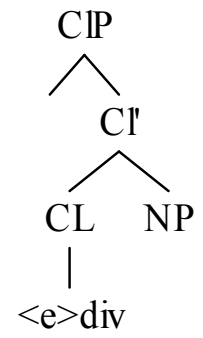

(13)

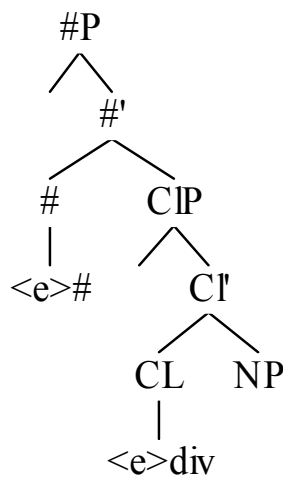

The structure of English nominals proposed by Borer is illustrated below. (14) shows non-quantity structures and (15) presents quantity structures.

5 There is a terminological point that must be made. In this paper, following Borer, a quantity phrase (\#P) simply refers to a phrase that has a quantity projection, which is different from Li's NumP (1998). Li (1998: 696) argues that number expressions such as wu-ge xiaohai 'five-CL child' have two different interpretations: quantity denoting (NumP) or individual-denoting (DP). For Li, wu-ge xiaohai in (i) is a quantity-denoting number expression, a NumP, which is not a "quantificational expression quantifying over individuals" (p. 700), and wu-ge xiaohai in (ii) is an individual-denoting expression, a DP. Her NumP is distinct from my \#P and her NumP examples are not discussed in this paper.

(i) Wu-ge xiaohai chi-bu-wan shi-wan fan.

five-CL child eat-not-finish ten-bowl rice

'Five children cannot finish ten bowls of rice.'

(ii) Zhangsan you wu-ge xiaohai.

Zhangsan have five-CL child

'Zhangsan has five children.' 
(14) English Non-Quantity (homogeneous) structures:
a. Determinerless Mass
$[\mathrm{NP}$ salt $]$
b. Determinerless Plural

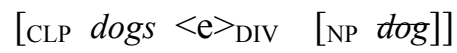

(15) English Quantity (non-homogeneous) structures:

a. Indefinite Mass

b. Indefinite Plurals

$$
\left[{ }_{\mathrm{p}} \text { much }<\mathrm{e}>_{\#} \quad[\mathrm{NP} \text { salt }]\right]
$$

c. Indefinite Singular

$\left[\# \mathrm{p}\right.$ many $<\mathrm{e}>_{\#} \quad\left[\mathrm{CLP} d o g s<>_{\mathrm{DIV}}[\mathrm{NP}\right.$ dog] $\left.]\right]$ $\left[{ }_{\# \mathrm{p}} a<\mathrm{e}>_{\#(\mathrm{DIV})} \quad\left[\mathrm{CLP} \quad \boldsymbol{a}<\mathrm{e}>_{\mathrm{DIV}(\#)}[\mathrm{NP} d o g]\right]\right]$

d. Definite Mass

$$
\text { [DP the }\langle\mathrm{e}\rangle_{\mathrm{d}}\left[\mathrm{Hp}_{\mathrm{p}} \text { the }\langle\mathrm{e}\rangle_{\#} \quad\right. \text { [NP salt]]] }
$$

e. Definite Plurals

[DP the $<\mathrm{e}>_{\mathrm{d}}\left[\text { [\#p }_{\mathrm{p}} \text { the }<\mathrm{e}\right\rangle_{\#} \quad$ [CLP $\left.\left.\left.d o g s<{ }_{\mathrm{DIV}}[\mathrm{NP} d o g]\right]\right]\right]$

f. Definite Singular

[DP the $\langle\mathrm{e}\rangle_{\mathrm{d}}$ [\#p the $\langle\mathrm{e}\rangle_{\#(\operatorname{DIV})}$ [CLP the $\left.\left.\left\langle\mathrm{e}>_{\mathrm{DIV}(\#)}[\mathrm{NP} d o g]\right]\right]\right]$

g. Definite Numeral Plurals

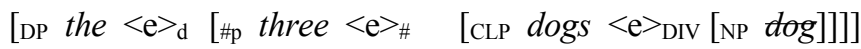

Bare nouns, salt and $\operatorname{dogs}$ in (14), have non-quantity structures because the \#P does not project. Without the ClP projection, a bare noun like salt in (14a) maintains its default mass interpretation. In contrast, the plural head feature realized as $-s$ will make a ClP projection in (14b). The CL head, which provides division to the nominal, will make a noun like dogs countable and ready to be counted. In other words, the ClP projection makes dogs countable although $\operatorname{dog} s$ is not counted for there is no counting element in this case, such as a determiner. Comparing (14a) and (14b), we can see that the projection of ClP determines the mass/count interpretation of a listeme.

In (15), the quantifiers much (15a) and many (15b), the indefinite article $a(15 \mathrm{c})$, and the definite article the (15d) are range assigners to $\langle\mathrm{e}\rangle_{\#}$ and the \#P projects. (15b) is like (14b) in that $d o g$ must join $-s$ to become $\operatorname{dog} s$. In $(15 \mathrm{c}), a$ is base-generated 
14 Mandarin Bare Classifier-Nouns: Towards a Universal Structure for

under $\mathrm{ClP}$ to assign range to $<\mathrm{e}>_{\mathrm{DIV}}$ and then raised to \#P to assign quantity value to the nominal. Another way to account for the behavior of $a$ is that $a$ in (15c) assigns range to $\langle\mathrm{e}\rangle_{\text {DIV }}$ and $<\mathrm{e}\rangle_{\#}$ simultaneously and heads the fused \#/ClP. For (15d) the salt, since there is no ClP projection, it will keep its default mass interpretation and according to Borer, when there is no other $\langle\mathrm{e}\rangle_{\#}$ range assigner, the definite article the will be generated in \#P to assign range to $\langle\mathrm{e}\rangle_{\#}$. The can be a $\langle\mathrm{e}\rangle_{\#}$ range assigner because, for Borer, the quantity information of definite phrases is interpreted anaphorically from the context or from the real world knowledge. Since the will provide the quantity reading anaphorically, the listeners will interpret the quantity for the salt (15d) from the context. In (15e) the dogs, the plural $-s$ projects the $\mathrm{ClP}$, which makes the dogs countable, and the assigns range to $<\mathrm{e}\rangle_{\#}$ since there is no other ranger assigners for $\left.<_{\mathrm{e}}\right\rangle_{\# \text {. As }}$. An (15d), the \#P in (15e) obtains its quantity interpretation anaphorically from the context. Notice that the may also assign range to $\langle\mathrm{e}\rangle_{\text {DIV }}$. When the assigns range to $<\mathrm{e}>_{\mathrm{DIV}},<\mathrm{e}>_{\#},<\mathrm{e}>_{\mathrm{d}}$ as in (15f), we will get a definite singular nominal such as the dog. The three dogs in $(15 \mathrm{~g})$ is an example of definite numeral plurals, in which $-s$ assigns range to $\langle\mathrm{e}\rangle_{\mathrm{DIV}}$, three to $\left.<_{\mathrm{e}}\right\rangle_{\#}$, and the to $\langle\mathrm{e}\rangle_{\mathrm{d}}$.

One important difference between the non-quantity structures in (14) and the quantity structures in (15) is that having a non-homogeneous structure makes these quantity nominals able to provide boundedness to events and thus contribute to the telic reading of a sentence. As shown in (16), houses (16a) has no quantity structure and contributes to atelic readings, while three houses (16b) is a nominal with quantity (\#P) and forces telic readings. In (17), only quantity phrases, like three pictures, are allowed in a telic sentence constructed by a telic predicate, such as painted up.

(16) a. Bill built houses.

b. Bill built three houses. 
(17) a. *Yesterday Kelly painted up pictures.

b. Yesterday Kelly painted up three pictures.

In her analysis of Mandarin nominals, Borer (2005a: 179) argues that Mandarin classifier is like English alan or every/each assigning range to both $\langle\mathrm{e}\rangle_{\#}$ and $\langle\mathrm{e}\rangle_{\text {DIV }}$, as exemplified in (18a). This argument is similar to that of Cheng \& Sybesma, as shown in the NumP structure (9a), in that when a Mandarin classifier exists, \#P must project. This, she believes, explains why a bare CL-N combination, ben shu 'CL-book,' always gets a singular interpretation. Based on her assumption, (18a) ben shu 'CL-book' means 'one book' and (18b) san ben shu 'three-CL-book' will be three sets of 'one book' with the numeral in the specifier position of the $\# \mathrm{P}$ as an adjunct. Examples $(18 \mathrm{c}, \mathrm{d})$ illustrate that using Borer's analysis for Mandarin, ban zhi ji 'half CL-chicken' will mean half of 'one chicken' and zhe zhi ji 'this CL-chicken' will mean this 'one chicken.'
(18) a. [\#p ben $<\mathrm{e}\rangle_{\#(\text { DIV })}$
$\mathrm{CL}$
$\left[\mathrm{CLP}\right.$ ben $<\mathrm{e}>_{\operatorname{DIV}(\#)}[\mathrm{NP}$ shu $\left.\left.]\right]\right]$ book
b. [\#p san [ ben $<\mathrm{e}>_{\#(\text { DIV })}\left[\mathrm{CLP}\right.$ ben $<\mathrm{e}>_{\operatorname{DIV}(\#)}[\mathrm{NP}$ shu ]]]] three $\mathrm{CL}$ book
c. [\#p ban [ zhi<e $\left.\left.\left.>_{\#(\text { DIV })}^{[\mathrm{CLP}} z h i<\mathrm{e}>_{\mathrm{DIV}(\#)}[\mathrm{NP} j i]\right]\right]\right]$ half $\mathrm{CL}$ chicken
d. [DP $\left.\left.z h e<\mathrm{e}>_{\mathrm{d}}\left[\#_{\mathrm{p}} z h i<\mathrm{e}\right\rangle_{\#(\mathrm{DIV})}\left[\mathrm{CLP} z h i<\mathrm{e}>_{\mathrm{DIV}(\#)}[\mathrm{NP} j i]\right]\right]\right]$ this CL
chicken

Comparing Borer's analysis of English in (14) and (15) and that of Mandarin in (18), I find that although she believes plural markers and classifiers are in complementary distribution in world languages, she has different analysis for English bare plural, dogs as a ClP, and for Mandarin bare CL-N, ben shu 'CL-Book' as a $\# / \mathrm{ClP}$. English numerals and quantifiers assign range to $\langle\mathrm{e}\rangle_{\#}$ and 
project \#P as in $(15 \mathrm{a}, \mathrm{b})$, but Mandarin numerals will be adjuncts to the \#P. With respect to definites, English definite article assigns range to $\langle\mathrm{e}\rangle_{\#}$ when there is no range assigner for $\left.<_{\mathrm{e}}\right\rangle_{\#}$, e.g., when there is no numeral as in the dogs. However, Mandarin (which does not have definite articles) demonstratives cannot assign range to $\langle\mathrm{e}\rangle_{\#}$ even when there are no numerals or quantifiers, as in (18d) zhe zhi ji 'this CL-chicken.' In Borer's proposal, an open value can only be assigned range once; therefore, since the

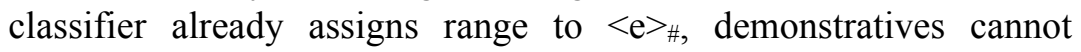
assign range to it at the same time. Borer's structural analyses for plural markers, classifiers, numerals, quantifiers, and definite markers are clearly different in English and in Mandarin. This paper argues that the Mandarin data is better explained by using Borer's analysis for English and the analysis for these two languages can be consistent.

Borer's proposal for Mandarin classifiers (2005a: 178-189) seems reasonable; yet, there are many problems regarding the evidence that her analysis is based upon.

The first issue concerns the generic interpretation of nominals. Borer argues that English generic interpretation requires a generic operator (GEN) assigning range to $\left.<_{\mathrm{e}}\right\rangle_{\#}$; therefore, only NP water and ClP lions can have generic reading as in (19a) and (19b). A \#P like two lions cannot have generic reading because the open value of $\langle\mathrm{e}\rangle_{\#}$ has been assigned range by two preventing the generic operator to provide genericity, as shown in (19c).

(19) a. GEN [DP $<\mathrm{e}>_{\mathrm{d}}\left[\#_{\mathrm{p}}<\mathrm{e}>_{\#}[\right.$ Water $\left.\left.]\right]\right] \ldots$ is important to human health.

b. GEN [DP $<\mathrm{e}>_{\mathrm{d}}\left[\#_{\mathrm{p}}<\mathrm{e}>_{\#}[\right.$ Lions ]]]. . . eat meat. c. ${ }^{*} \mathrm{GEN}\left[\mathrm{DP}<\mathrm{e}>_{\mathrm{d}}\left[{ }_{\mathrm{p}} \text { Two }<\mathrm{e}\right\rangle_{\#}[\right.$ lions ]]] . . . eat meat.

Borer believes that Mandarin CL must assign range to $<\mathrm{e}\rangle_{\#}$ and $<\mathrm{e}\rangle_{\text {DIV }}$, which makes generic interpretation impossible for CL-Ns as shown in Cheng \& Sybesma (1999, 2005). Cheng \& Sybesma's 
problem is that they only consider the nominals in the pre-verbal subject positions for generic interpretation, but CL-Ns can only appear in post-verbal positions in Mandarin that is perhaps why they did not notice generic CL-N cases. Bare CL-Ns do have generic readings in sentences like (20).

(20) Lisi wanfan hou xihuan he bei jiu.
Lisi dinner after like drink CL wine
'Lisi likes to have wine after dinner.'

In addition, this generalization about the incompatibility of GEN operator and overt numerals may be incorrect. This generalization cannot explain a sentence like (21), in which a potato, for Borer, is a quantity phrase and still gets generic interpretation. I will argue later that Mandarin $\mathrm{CL}$ assigns range only to $\langle\mathrm{e}\rangle_{\text {DIV }}$ and this accounts for the fact that $\mathrm{ClP}$ allows generic interpretation in Mandarin.

(21) A potato contains vitamin C.

The second problem comes from Borer's belief about CL-Ns being interpreted only as singular. Borer (2005a: 180) argues that Mandarin bare CL-Ns 'are always interpreted as singulars' so \#P must project. The problem is that if CL-N always gets a singular 'one' interpretation, a quantity interpretation, why CL-N cannot appear in telic sentences. We will see later that predicate CL-Ns do not always get singular interpretation.

The third issue originates from Borer's argument that various Chinese languages have a general classifier for the unspecified plural (e.g., Mandarin xie 'some'), as illustrated in (22). Borer argues that Mandarin plural CL-Ns, unlike English bare plurals, are quantity expressions; therefore \#P must project for this plural CL-N. She takes this as evidence that \#P projects for all Mandarin 
CL-Ns.

$\begin{array}{lcccc}\text { Wo } & \text { xiang } & \text { mai } & \text { xie } & \text { shu. } \\ \text { I } & \text { want } & \text { buy } & \text { XIE } & \text { book } \\ \text { 'I want to buy } & \text { some books.' }\end{array}$

Even though I agree that $x i e-\mathrm{N}$ is a quantity expression, it needs not to be the case that xie assigns range to both $\left.<_{\mathrm{e}}\right\rangle_{\#}$ and $\langle\mathrm{e}\rangle_{\text {DIV }}$ as Borer suggests. It can be the case that xie assigns range to $<\mathrm{e}\rangle_{\#}$ just like other quantifiers such as henduo 'much, many' and there needs not be CL projection. Considering the examples below, I argue that xie is not a classifier and thus whether it conveys quantity or not cannot be a piece of evidence to argue for the \#P projection of Mandarin classifiers. That there are at least six reasons to argue against xie as a classifier claimed by previous studies (Li \& Thompson 1981, Borer 2005a, Cheng \& Sybesma 2005).

First, when $y i$ 'one' appears with classifiers, the unit it picks up must be a naturally measurable unit. For instance, yi-ge pingguo 'one-CL apple' only refers to an apple, not a slice of apple. Therefore, if xie is a classifier and yi-xie means 'some,' the only possible reading for (23a) and (23b) will be 'some whole apples' and 'some whole dogs,' not 'some pieces of apples' or 'some pieces of dogs.' I argue that because xie is not a classifier, its lack of classifier projection, which offers division function, makes a noun keep its default mass interpretation. The lack of a divider such as a classifier accounts for the possibility of ambiguity for (23a) and (23b).

Unlike other classifiers, xie does not unambiguously create naturally measurable units that can be counted. Yixie 'some' is a quantifier like henduo 'much, many' assigning range to $\langle\mathrm{e}\rangle_{\#}$ and heading the $\# \mathrm{P}$ and there is no CL projection. 
(23)

a. $[\text { yixie }<\mathrm{e}\rangle_{\#} \quad[$ pingguo $\left.]\right]$

one-XIE apple

'some apples' (ambiguous between whole fruits or pieces of apples)

b. $\left[\begin{array}{ll}\text { yixie }<{ }^{\prime}>_{\#} & [\text { gou }]]\end{array}\right.$

$$
\text { one-XIE dog }
$$

'some dogs' (ambiguous between individual dogs or pieces of a dog as in a context of putting the puzzles of a dog together)

Second, to call xie a 'plural classifier' is clearly a misnomer since it does not 'classify' any nouns. Classifiers are called classifiers because the nouns they modify constitute a class. For example, Mandarin classifier 'tiao' only modifies long and slim objects such as belts and scarves. All classifiers appear with particular nouns, as illustrated in (24a-d). There are no classifiers that can appear with all nouns; even the general classifier ge does not have such a broad applicability. The general classifier ge is not applicable for mao 'cat' and luomanshi 'romance' in (24b) and (24d). But unlike classifiers, yixie 'some' can appear with almost all kind of nouns, such as juzi 'orange,' mao 'cat,' xiangfa 'thought,' and luomanshi 'romance' in (25), and the nouns that appear with it do not form any class. There is no selectional restriction between xie and nouns; therefore, xie is not likely to be a classifier as claimed by previous researchers.
(24)
a. yi-ke/ge juzi one-CL/CL orange
b. yi-zhi/*ge mao one-CL/CL cat



c. yi-ge
xiangfa
one-CL
thought
d. yi-chang/*ge
luomanshi one-CL/CL
romance

(25) yixie juzi/mao/xiangfa/luomanshi
some

Third, xie does not behave like other classifiers that include more than one object into a countable unit, such as $d a{ }^{\prime} \mathrm{CL}^{\text {DOZEN }}$, or qun ' $\mathrm{CL}$ FLOCK, in (26). These words can be called classifiers because they do classify and they impose selectional restriction to the subsequent nouns. Unlike these classifiers, xie cannot appear with quantifiers, such as mei 'every,' which is semantically singular and specifying singular 'sets.'
(26) a. Mei da meigui mai 20 kuai qian. every $C^{\text {DOZEN }}$ rose sell 20 dollar money 'Every dozen of roses sells for 20 dollars.'

b. Mei qun yanzi dou paichu meili every $\mathrm{CL}^{\mathrm{FLOCK}}$ swallow all lay:out beautiful de tu'an.

DE picture

'Every flock of swallows lays out a beautiful picture.'

c. *mei xie

every $\mathrm{CL}^{\mathrm{PL}}$

Fourth, one way to ask for quantity is to use $j i$ 'how many' in the position of numerals, which immediately precedes classifiers, as shown in (27). Sentences in (28) show that $j i$ cannot appear 
with xie. This again makes xie distinct from all other classifiers.
a. $\mathrm{Ni}$ you ji
ji zhi
bi? you have how:many CL 'How many pens do you have?'
b. Wo
you
wu
zhi
bi.
I have five
CL
pen
'I have five pens.'

(28)
a. $* \mathrm{Ni}$ you $\mathrm{ji}$
xie
bi? you have
$\mathrm{CL}^{\mathrm{PL}}$
pen
b. Wo you yixie bi. I have some pen 'I have some pens.'

Fifth, xie cannot be reduplicated as other classifiers, which is argued to be the test of 'classifier-hood' (Hu 1958). The classifier $k e$ for apples can appear in the reduplication forms, as exemplified in (29), while xie is not allowed in this reduplication construction, as shown in (30).
a. yi ke pingguo one $\mathrm{CL}$ apple 'one apple'

b. Yi ke ke pingguo dou bian hong le. one CL CL apple all become red SFP 'All the apples became red.' 
22 Mandarin Bare Classifier-Nouns: Towards a Universal Structure for

$\begin{array}{llllll}\text { c. Meimei } & \text { zai } & \text { zhi } & \text { shang } & \text { hua } & \text { chu } \\ \text { little:sister } & \text { at } & \text { paper } & \text { on } & \text { draw } & \text { out } \\ \text { yi } & \text { ke } & \text { yi } & \text { ke } & \text { de } & \text { pingguo. } \\ \text { one } & \text { CL } & \text { one } & \text { CL } & \text { DE } & \text { apple }\end{array}$

'Little sister drew out apples (one by one) on the paper.'

(30)
a. yi xie
pingguo
some
apples

b. ?yi xie xie pingguo

a few

apples

\begin{tabular}{|c|c|}
\hline ie & yi xie \\
\hline some & some \\
\hline
\end{tabular}

Sixth, xie can only appear with $y i$ 'one,' not with other numbers. Here $y i$ does not convey the numeral meaning 'one.' $Y i$ is like an inseparable part of the word, yixie 'some.' Many other Mandarin words have the part $y i$ 'one,' such as yiqi 'together,' yigong 'total,' yiqie 'everything,' yizhi 'identical,' and so on. It does not seem reasonable to analyze yixie as 'one-CL ${ }^{\mathrm{PL}}$, since $y i$ cannot be substituted by other numerals. ${ }^{6}$

The observations above clearly show that xie is not a classifier for it does not have the properties of a classifier. Yixie 'some' is like other quantifiers such as suoyoude 'all' or henduo 'much, many' that may take various kinds of nouns, unlike classifiers, which have selectional restriction for the type of nouns they can co-occur. Xie does not support Borer's proposal that Mandarin

6 Yixie 'some' is not like Spanish unas 'some,' which can be analyzed as una 'one' plus plural $-s$. Yixie is a listeme, not a combination of $y i$ 'one' and xie ' $\mathrm{CL}^{\mathrm{pl}}$.' Zhexie 'these' and naxie 'those' are variants of zhe-yixie 'this-some' and na-yixie 'that-some.' 
classifiers assign range to both $\langle\mathrm{e}\rangle_{\#}$ and $\left.<\mathrm{e}\right\rangle_{\text {DIV }}$.

The fourth problem of Borer involves her analysis of Mandarin demonstratives. She argues that the fact that demonstrative- $N$ without a classifier can have a singular or plural reading, as in (31), also supports the proposal that Mandarin classifier assigns

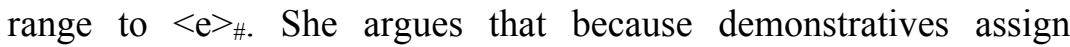
range to $\langle\mathrm{e}\rangle_{\#}$ (like English definite articles, obtaining quantity information anaphorically) and sometimes to $\langle\mathrm{e}\rangle_{\text {DIV }}$, the classifiers (assigning range to $\langle\mathrm{e}\rangle_{\#}$ and $\langle\mathrm{e}\rangle_{\text {DIV }}$ ) can be absent.
(31) $\mathrm{Ni}$
zhe $\quad$ in
dei
cheng yi-xia.
you
this
letter
must
weigh a-bit
'This/these letter(s) of yours must be weighed.'
$(=$ Borer 2005a: 182 ex. $(46)=$ Cheng \& Sybesma 2005: 275 ex. (30))

Borer's idea can be exemplified in (32a): when the classifier appears, the demonstrative zhe 'this' is generated in D. When there is no classifier, zhe will be base generated in ClP and move up to \#P and then DP to assign ranges to $\left.\langle\mathrm{e}\rangle_{\mathrm{d}}<\mathrm{e}\right\rangle_{\#}$ and $\left.<\mathrm{e}\right\rangle_{\text {DIV. }}$
a. [DP $z h e<\mathrm{e}>_{\mathrm{d}}\left[\#_{\mathrm{p}} \text { fen }<\mathrm{e}\right\rangle_{\#(\mathrm{DIV})}$ [CLP fen $<\mathrm{e}>_{\mathrm{DIV}(\#)}$ [NP xin ]]]] this $\mathrm{CL}$ letter 'this letter'
b. [DP $z h e\langle\mathrm{e}\rangle_{\mathrm{d}}\left[{ }_{\mathrm{p}} z h e<\mathrm{e}\right\rangle_{\#(\mathrm{DIV})}\left[\mathrm{CLP}\right.$ zhe $\langle\mathrm{e}\rangle_{\mathrm{DIV}(\#)}[\mathrm{NP}$ xin ]]]] this letter 'this letter / these letters'

Although this analysis does not have a problem in itself, it is widely accepted that in the presence of a demonstrative a classifier must be present (Chao 1968). Therefore, zhe xin 'this letter' without a classifier in (31) and (32b) is a special demonstrative case that may express only a deictic function rather than a quantity 
function. Recall that demonstratives dominate $\langle\mathrm{e}\rangle_{\mathrm{d}}$ and $\langle\mathrm{e}\rangle_{\#}$ because definite phrases obtain their quantity information anaphorically from the context or the real world situation. I propose that only DP, \#P, NP, but no ClP project for zhe xin 'this letter' and whether the listeners interpret the phrase as singular or plural depends on the context, as in (33). Other examples without classifiers, (34), also support my analysis that demonstratives assign range to $\langle\mathrm{e}\rangle_{\mathrm{d}}$ and $\langle\mathrm{e}\rangle_{\#}$, but not to $\langle\mathrm{e}\rangle_{\text {DIV. }}{ }^{7}$

$$
\begin{aligned}
& \text { [DP } \text { zhe }\langle\mathrm{e}\rangle_{\mathrm{d}}\left[\mathrm{Hp}_{\mathrm{p}} \text { the }<\mathrm{e}\right\rangle_{\#}[\mathrm{NP} \text { xin ]]] } \\
& \text { this letter } \\
& \text { 'this letter / these letters' }
\end{aligned}
$$

7 Adopting Borer's analysis of English definites, I argue that Mandarin demonstratives head a DP and may assign range to $\langle\mathrm{e}\rangle_{\mathrm{d}}$ and $\langle\mathrm{e}\rangle_{\# \text {. Demonstrative }}$ phrases may provide quantity reading, which contributes to the boundedness of telic sentences. Liu (2003: 13) has a different analysis for Mandarin demonstratives. She argues that "in Chinese, definite NPs behave differently from quantified, numeral NPs with respect to diagnostics of telicity, despite the fact that both types of NPs provide an inherent final point for an event," as shown in (i). Since demonstrative-CL-N does not pass the test of telicity, she argues that Mandarin demonstrative-CL-N provides boundedness for sentences may be because of its definiteness, not because of its quantity.

(i) Zhangsan neng zai yi nian nei gai san-dong fangzi / *na-dong fangzi. Zhangsan can in one year in build three-CL house / that-CL house

'Zhangsan can build three houses / that house in one year.'

The distinction between numeral and demonstrative nominals is also observed in Soh \& Kuo (2005). They find that although the intuitive reading for accomplishment sentences with a numeral or a demonstrative nominal is a completed event, it is acceptable to add an assertion stating that the event is not completed when the sentence has a demonstrative nominal, but not so for a numeral nominal, as shown in (ii).

(ii) Wo zuotian kan-le ??san-ben shu / na-ben shu, keshi mei kan-wan. I yesterday read-LE three-CL book / that-CL book, but not read-finish 'Yesterday I read three books / that book, but I did not finish them/it.' 
(34) a. [DP Zhe $\langle\mathrm{e}\rangle_{\mathrm{d}}\left[\right.$ \#p $_{\mathrm{p}}$ Zhe $\langle\mathrm{e}\rangle_{\#}[\mathrm{NP}$ shui ]]] shi shei de? this water be whose 'Whose water is this?' (There may be one or more than one bottle of water.)

b. [DP Zhe $<\mathrm{e}>_{\mathrm{d}}\left[{ }_{\text {\#p }} \text { Zhe }<\mathrm{e}\right\rangle_{\#}[\mathrm{NP}$ shu ]]] zheme this book why
daochu
luan diu?
everywhere messy throw
'Why the book(s) are thrown everywhere?' (There may be one or more than one book.)

Borer's analysis for the special cases where Mandarin demonstratives and classifiers do not co-occur, for which she argues that both demonstratives and classifiers assign range to $\langle\mathrm{e}\rangle_{\#}$ and $\langle\mathrm{e}\rangle_{\text {DIV }}$, may not be the only possible analysis. These demonstrative cases do not argue for Borer's theory that classifiers assign range to $<\mathrm{e}\rangle_{\#}$ and $<\mathrm{e}>_{\text {DIV }}$.

The fifth piece of evidence that Borer uses to support her analysis for Mandarin classifiers involves classifier reduplication, as shown in (35a). She assumes this classifier reduplication gives rise to a distributive universal quantification reading, namely the each/every reading, as is stated in Cheng \& Sybesma (2005), Hu (1958), and $\mathrm{Li} \&$ Thompson (1981). Borer argues that her assumption that Mandarin classifiers assigning range to $\left.<_{\mathrm{e}}\right\rangle_{\#}$ and $\langle\mathrm{e}\rangle_{\text {DIV }}$ at the same time can give this universal quantification structure a natural account. Her analysis of classifier reduplication is shown in (35b).

a. Ge-ge xuesheng dou $\quad \begin{aligned} & \text { buyiyang. } \\ & \text { CL-CL student }\end{aligned}$
'Every student is different.'


b. [DP ge-ge $\langle\mathrm{e}\rangle_{\mathrm{d}}\left[\text { \#p }_{\mathrm{p}} g e-g e<\mathrm{e}\right\rangle_{\text {\#(DIV })}\left[\mathrm{CLP}\right.$ ge-ge $\langle\mathrm{e}\rangle_{\mathrm{DIV}(\#)}$ [NP xuesheng]]]] CL-CL student 'every student'

However, as pointed out by Cheng (2005), CL-CL-N is very rare and restricted in modern Mandarin. I suggest this construction as an idiomatic use, which does not provide powerful support to a theory. Besides, if CL-CL does express universal quantification, what is the function of $y i$-CL-CL? Is $y i$-CL-CL, the un-abbreviated form for CL-CL? The appearance of $y i$ 'one' in $y i$-CL-CL will not cause any problem for Borer's analysis because $y i$ 'one' is in the specifier position of the \#P so $y i$-CL-CL still projects as a \#P. But, CL-CL and yi-CL-CL behave differently. Contrary to Borer's claim that Mandarin CL-CL has distributive universal reading, I find that CL-CL provides collective universal quantification, the all reading, as in (36a), while $y i$-CL-CL provides the distributive universal reading, the each/every reading, as in $(36 \mathrm{~b}, \mathrm{c})$. The collective universal CL-CL (36a) allows exceptions, but the distributive universal yi-CL-CL (36b) does not.

(36) a. women xuexiao ge-ge xuesheng dou hen we school CL-CL student all very youxiu, zhishi you yi liang-ge liwai. outstanding, but have one two-CL exception 'In our school, all students are outstanding, but there are one or two exceptions.'

$\begin{array}{lllll}\text { b. *Women } & \text { xuexiao } & \text { yi } & \text { ge-ge } & \text { xuesheng } \\ \text { we } & \text { school } & \text { one } & \text { CL-CL } & \text { student } \\ \text { dou } & \text { hen } & \text { youxiu, } & \text { zhishi } & \text { you } \\ \text { all } & \text { very } & \text { outstanding, } & \text { but } & \text { have } \\ \text { yi } & \text { liang-ge } & \text { liwai. } & & \\ \text { one } & \text { two-CL } & \text { exception } & & \end{array}$


'In our school, each student is outstanding, but there are one or two exceptions.'

c.

$\begin{array}{llll}\text { Women } & \text { xuexiao } & \text { yi } & \text { ge-ge } \\ \text { we } & \text { school } & \text { one } & \text { CL-CL } \\ \text { xuesheng } & \text { dou } & \text { hen } & \text { youxiu. } \\ \text { student } & \text { all } & \text { very } & \text { outstanding }\end{array}$

'In our school, each student is outstanding.'

As can be seen in (36a), CL-CL must co-occur with the universal adverb dou 'all.' A CL-CL construction without dou is ungrammatical, as in (37a). Yet (37b), which has yi-CL-CL without dou 'all,' is grammatical because this example does not have universal quantification reading. It is interesting that $y i$-CL-CL does not always express universal quantification. In a sentence without the universal adverb dou, bare CL-CL is not allowed as in (37a) and $y i$-CL-CL means 'many' in (37b) and 'one after another' in (38). The universal quantification reading is not possible for $y i$ 'one'-CL-CL in (37) and (38). These examples seem to suggest that the universal reading of CL-CL and $y i$ 'one'-CL-CL in (36) is related to dou 'all' - a fact not captured by Borer's structure.

a. Wo I

zai

in

b.

$\begin{array}{llll}\text { *Wo } & \text { kanjian } & \text { yi } & \text { ge-ge } \\ \text { I } & \text { see } & \text { one } & \text { CL-CL } \\ \text { xuesheng } & \text { zai } & \text { paobu. } & \\ \text { student } & \text { in } & \text { run } & \\ \text { 'I see many students running.' } & \\ \text { 'I see each student running.' (not a possible reading) }\end{array}$

xuesheng

CL-CL student

paobu.

run 
(38) *(Yi) ge-ge xuesheng zou jin-le jiaoshi. one CL-CL student walk enter-LE classroom 'Students walked into the classroom one after another.'

Last but not least, my main concern for Borer's analysis is that if Mandarin CL is like English a/an or every/each assigning range to $<\mathrm{e}>_{\#}<\mathrm{e}>_{\text {DIV }}$, heading the \#P (or \#/ClP), and obtaining singular interpretation as English a/an, why bare CL-Ns cannot appear in telic sentences in (39)? If CL-Ns are \#Ps, the sentences in (39) will contradict Borer's proposal that quantity phrases may contribute to the telic reading.

a. Lisi kao-hao-le Lisi bake-finish-LE *(yi)-ge dangao. 'Lisi baked up a cake.'

b. Lisi

$$
\text { zai }
$$

Lisi

ZAI

nei

kao-hao

*(one)-CL cake

in

bake-finish

yi

xiaoshi

one

hour

'Lisi (can) bake up a cake in one hour.'

Besides, if both classifiers and numeral-classifiers project \#P (numerals as the specifier of the $\# \mathrm{P}$ ), ge ' $\mathrm{CL}$ ' (40b) and yi-ge 'one-CL' (40c) will head a \#P and both should be acceptable answers to the question (40a). This is obviously not the case.
a. $\mathrm{Ni}$ chi-le pingguo le ma? you eat-LE apple SFP QP 'Have you had apples?' 


$\begin{array}{lll}\text { b. }{ }^{* W o} & \text { chi-le } & \text { ge. } \\ \text { I } & \text { eat-LE } & \text { CL } \\ \text { c. Wo chi-le } & \text { yi-ge. } \\ \text { I } & \text { eat-LE } & \text { one-CL } \\ \text { 'I ate one.' } & \end{array}$

In sum, section 2 discusses some of the previous analyses of CL-N in argumental positions. The phonological reduction analysis of Chao argues that $y i$-CL-Ns can be phonological reduced to CL-Ns. Yang's covert numeral analysis is similar to the $y i$ 'one' omission analysis, but she also proposes an alternative analysis, which she suggests to treat the bare $\mathrm{CL}$ as a clitic to the preceding verb. Cheng \& Sybesma find that $y i$-CL-Ns cannot always be reduced to CL-Ns and they argue that CL-Ns are prohibited in telic sentences because of their being non-specific. Section 2.4 focuses on Borer's proposal that Mandarin classifiers head the \#/ClP because they simultaneously convey the meaning 'one,' which projects $\# \mathrm{P}$, and provide the dividing function, which projects ClP. All of the analyses above have explanatory limitations and I have provided evidence against Borer's analysis for Mandarin. In section 3, I will argue that Borer's analysis for English plural morphology can be adopted for Mandarin classifiers and there is no need to propose a different analysis for Mandarin classifiers.

\section{Proposal: Classifier-Noun as CIP}

Following Borer's framework (2005a, b), but deviating from her analysis of Mandarin, I will draw a parallel between the English plural morphology and Mandarin classifiers and argue that CL-Ns in Mandarin behave partially like bare plurals in English in their 
(i) inability to contribute to the telic interpretation of a VP; (ii) lack of specific readings (or lack of specificity and referentiality over all in predicate positions); (iii) ability to appear in non-argument positions.

Classifier morphology and plural inflection are in complementary distribution cross-linguistically; therefore, Borer (2005a: 93-94) argues that 'plural inflection is classifier inflection.' She claims that English plural inflection functions as classifiers in that both head the ClP. The idea to argue that English plural marker and Mandarin CL have the same structure is also supported by Peyraube's (1998) observation that 'the development of count-classifiers in Chinese is related to the loss of an element which may have been a plurality marker.'

The current proposal argues for a CIP and non-quantity structure for CL-Ns. First, mandarin CL assigns range to $\langle\mathrm{e}\rangle_{\text {DIV }}$ and heads the ClP. This is briefly mentioned in Borer (2005a: 178), but unfortunately, without getting into any details of this analysis, she soon argues for another analysis - Mandarin CL assigns range to $<\mathrm{e}\rangle_{\#}$ and $<\mathrm{e}>_{\text {DIV }}$ and heads \#/ClP - which in fact has some problems as discussed in section 2. Second, in the current analysis, the Mandarin CL system is like the English CL system creating units that are ready to be counted. The structure of Mandarin zhi-gou 'CL-dog' is like that of English dogs in that both are ClPs carrying no quantity information and therefore unable to contribute to the telic reading of a VP. Quantity information is carried by numerals or quantifiers in a \#P, such as san ben-shu 'three-CL book.' Accordingly, the following interpretations are predicted:

\begin{tabular}{lll} 
& Mandarin & English \\
\hline ClP & CL cat & cats \\
$\# P$ & one-CL cat & one cat \\
$\# P$ & two-CL cat & two cats
\end{tabular}


I also argue that it is the lack of quantity structure that makes CL-Ns only acceptable in atelic predicates, not the lack of specificity as claimed by Cheng \& Sybesma. The lack of specificity of CL-Ns comes from the lack of quantity. This will account not only for the argumental cases, but also for the non-argumental cases. The structures of Mandarin nominals are proposed as follows.

(42) Non-Quantity (homogeneous) structures:

a. Mass

[NP yan 'salt'] 'salt'

b. Count [CLP $z h i$ 'CL' <e $>$ DIV [NP gou 'dog'] 'CL dog'

c. Countable mass [CLP ping ' $\mathrm{CL}$ ' $<\mathrm{e}>\mathrm{DIV}$ [NP yan 'salt']] 'bottle salt'

(43) Quantity (non-homogeneous) structures:

a. Indefinite Mass

[\#P henduo 'much' $<\mathrm{e}>_{\#}$

[NP yan 'salt']]

'much salt'

b. Indefinite Count

[\#P henduo 'many' <e $>_{\#}[\mathrm{CLP} z h i$ 'CL' $<\mathrm{e}>\mathrm{DIV}$ [NP gou 'dog']]] 'many dogs'

c. Indefinite Singular

[\#P $y i$ 'one' $<\mathrm{e}>_{\#} \quad$ [CLP $z h i$ 'CL' $<\mathrm{e}>_{\text {DIV }}[\mathrm{NP} g o u$ 'dog']] 'one dog'

d. Definite Mass

[DP zhe 'this' $<\mathrm{e}>_{\mathrm{d}}\left[\# \mathrm{P}\right.$ zhe 'this' $<\mathrm{e}>_{\#}$

[NP yan 'salt']]] 'this salt'

e. Definite Count

[DP $z h e$ 'this' $<\mathrm{e}>_{\mathrm{d}}$ [\#P $z$ the 'this' $<\mathrm{e}>_{\#}\left[\right.$ [CLP $z h i$ 'CL' $<\mathrm{e}>_{\text {DIV }}$ [NP gou 'dog']]]] 'this dog'

f. Definite Numeral Count

[DP $z h e$ 'this' $<\mathrm{e}>_{\mathrm{d}}\left[\# \mathrm{P} w u\right.$ 'five' $<\mathrm{e}>_{\#} \quad\left[\right.$ CLP $z h i$ 'CL' $<\mathrm{e}>_{\text {DIV }}$ [NP gou 'dog']]]] 'these five dogs'

A noun without ClP projection, as (42a) yan 'salt,' will provide 
the default mass interpretation. The projection of CIP indicates the countability of a noun. Without classifiers, such as zhi and ping, that create countable units from nouns, all nouns will have mass interpretation by default. Examples (42a-c) have non-quantity structures and provide homogeneous readings because there are no \#P projection. Quantifiers, numerals, and demonstratives, such as henduo 'much/many,' yi 'one,' zhe 'this,' san 'three' in (43), are range assigners to $\langle\mathrm{e}\rangle_{\#}$ and will project \#Ps, which have non-homogeneous structures and will contribute to the boundedness of events.

I assume that CL-Ns are ClPs having no quantity information; therefore, like bare Ns, they should have a non-quantity, homogeneous structure. ${ }^{8,9}$ Consequently, a bare activity V-CL-N construction without any aspectual markers, such as kan ben shu 'read-CL book,' should behave like the activity V-N kan shu 'read book' allowing atelic interpretation only. Telic reading will not be possible for kan shu 'read book' and kan ben shu 'read-CL book' unless they appear with aspectual markers or occur in some particular context. The in X time test (Dowty 1979) has proved to be a good test for telicity. This test confirms that the structures of bare $\mathrm{N}$ and CL-N are homogeneous and they do not contribute to telic interpretations and hence cannot appear in the in $X$ time construction. Bare $\mathrm{N}$ and $\mathrm{CL}-\mathrm{N}$ result in the ungrammatical sentence in (44a), while Num-CL-N has no problem appearing in a telic sentence with bounded time frame in (44b).

8 Borer (2005b: 75) argues that 'for bare plurals, there was division . . . but that division left an output that was neither uniform nor "quantitied," in the absence of a quantity phrase.' Since classifier and plural inflection share the same function, CL-N is not quantized, either.

9 Mandarin bare nouns can be interpreted as indefinite, definite, or generic. In this paper, 'bare nouns' refer to the indefinite bare nouns, unless specified. 
(44)

$\begin{array}{llll}\text { a. *Xiaoming } & \text { zai } & \text { shi } & \text { fenzhong } \\ \text { Xiaoming } & \text { in } & 10 & \text { minute } \\ \text { nei } & \text { kan shu/ben shu. } & \\ \text { inside } & \text { read book/CL book } & \\ \text { '*Xiaoming reads books in 10 minutes.' }\end{array}$

$\begin{array}{llll}\text { b. Xiaoming } & \text { zai } & \text { shi } & \text { fenzhong } \\ \text { Xiaoming } & \text { in } & 10 & \text { minute } \\ \text { nei } & \text { kan } & \text { yi/san-ben } & \text { shu. } \\ \text { inside } & \text { read } & \text { one/three-CL } & \text { book } \\ \text { 'Xiaoming reads one/three books in } & 10 \text { minutes.' }\end{array}$

Section 2.3 proposes that the lack of quantity of CL-Ns results in the lack of specificity. If this proposal is correct, the following prediction (45) will come out true. The prediction is exemplified in (46) for ClP, which does not have quantity or specificity, and in (47) for \#P, which may be specific (47a) or non-specific (47b).

(45) i. For ClP: Since there is no quantity, then no specificity.

ii. For \#P: Quantity appears, but specificity does not necessarily appear. ${ }^{10}$

(46) ClP: no quantity, no specificity

a. Mali xiang zhi mao yiyang ai chi yu. Mary as CL cat same love eat fish 'Mary loves to eat fish as much as a cat (cats).'

\footnotetext{
${ }^{10}$ In other words, if A, then B. If B, not necessarily A.

If no quantity, then no specificity.

$\rightarrow$ If specificity appears, then quantity must appear.

$\rightarrow$ When quantity appears, specificity not necessarily appears.
} 
34 Mandarin Bare Classifier-Nouns: Towards a Universal Structure for

b. Zhen wuliao, wo xiang kan chang dianying. really bored, I want see CL movie 'So bored! I want to see a movie (movies).'

(47) \#P: quantity, not necessarily specificity

a. Wo zuotian xi-le san-jian waitao. I yesterday wash-LE three-CL jacket 'I washed three jackets yesterday.'

b. Mali kao-le yi-ge dangao lai canjia bisai, Mali bake-LE one-CL cake come attend contest, keshi wo bu zhidao shi na yi-ge. but I not know be which one-CL 'Mali baked a cake to compete in the contest, but I don't know which one.'

This prediction is consistent with the common belief that \#Ps may be specific or non-specific. Telic predicates require quantity, but not necessarily specificity. If this hypothesis is on the right track, it is predicted that ClPs can appear in the places where specificity is irrelevant. For example, the generic sentence (48) provides a non-referential CL-N example, in which gen yan 'CL-cigarette' refers to kind and not to any single object and therefore its specificity is not relevant. More examples can be found in English bare plural predicates and Mandarin CL-N predicates, which are usually non-referential (denoting a property, not an entity) and thus it is irrelevant to talk about specificity.

(48) Zhangsan meitian wanfan hou chou gen yan. Zhangsan every:day dinner after smoke CL cigarette 'Zhangsan has cigarettes after dinner every day.' 
Besides, specificity is not a good way to account for the distribution of CL-N and Num-CL-N. Num-CL-N can be interpreted as specific or non-specific so it should be able to appear wherever the non-specific CL-N is allowed, but as discussed so far, CL-N and Num-CL-N do appear in different constructions. The structural proposal for Mandarin nominals in this paper will correctly predict that CL-N and Num-CL-N will have different distribution in Mandarin because they have different structures.

In addition, if Borer is correct that classifiers and plural morphology share the same function - both projects CIP without quantity - we should find Mandarin CL-Ns behaving like English bare plurals in argumental (49) and non-argumental positions (50).

$\begin{array}{llllll}\text { (49) Wo } & \text { xiang chi } & \text { kuai } & \text { binggan. } & \text { (argument) } \\ \text { I } & \text { want } & \text { eat } & \text { CL } & \text { cookie } & \end{array}$ 'I want to eat a cookie/cookies.'

(50) Wo changchang lei-de xiang zhi gou. (non-argument) I usually tired-DE as CL dog 'I am usually as tired as a dog/dogs.'

Even though I predict that Mandarin CL-N may behave like English bare plurals, Mandarin CL-N does not always behave like Mandarin bare N. Mandarin bare N and CL-N predicates have different interpretations. For example, in context (51), the referent has been mentioned in (51a) so (51b) requires a bare noun to express definiteness. Using CL-N as in (51c) will result in an infelicitous response, which is an indefinite and non-specific statement about occupation. 
(51) Nana shows her class picture to her friend, Mimi.

a. Mimi: (pointing to a man in the picture) 'Zhe-ge xuesheng hen ke'ai.' this-CL student very cute 'This student is very cute.'

b. Nana: 'Ta shi laoshi.' he be teacher

'He is the teacher.'

$\begin{array}{cccc}\text { c. Nana: '\#Ta } & \text { shi } & \text { CL } & \text { laoshi.' } \\ \text { he } & \text { be } & \text { CL } & \text { teacher }\end{array}$

'He is a teacher.'

Mandarin CL-N tends to express professions or roles for the subject and it is infelicitous to use a bare $\mathrm{N}$ for this purpose, as illustrated in (52). In (52), since (52a) is clearly asking the profession of the man, (52b) must use a CL-N to introduce the profession of the referent. It is infelicitous to answer with a bare $\mathrm{N}$ predicate (52c), which has a definite reading here. (52d) shows a possible answer to (52a), which also argues for the bare $\mathrm{N}$ to have definite reading in this context.

(52) Nana shows her high school reunion picture to her family.

a. Mom: 'Zhe-ge nasheng hen shui.

$\begin{array}{lllll}\text { this-CL } & \text { man } & \text { very } & \text { handsome } & \\ \text { Ta } & \text { shi } & \text { zuo } & \text { shenme } & \text { de?' } \\ \text { he } & \text { be } & \text { do } & \text { what } & \text { DE }\end{array}$

'This man is very handsome. What does he do?' 
b. Nana: 'Ta shi ge yisheng.' he be $\mathrm{CL}$ doctor

'He is a doctor.'

c. Nana: \#‘Ta shi yisheng.' he be doctor

'He is the doctor.'

d. Nana: 'Ma, bei zai bang wo

Mom, don't again for I

zuomei le. Ta shi laoshi.'

match:making SFP he be teacher

'Mom, don't do match-making for me again!

He is the (our) teacher.'

In sum, the current proposal for Mandarin nominals can be schematized in (53) to (55). ${ }^{11}$

(53) Predicate CL-N
a. $\mathrm{ClP}$

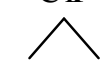
b. Mali shi ge daxuesheng.
Mali be CL college:student
'Mary is a college student.'

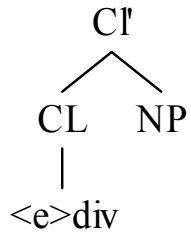
- No D
- No referential reading
- Count(able), but not counted

11 Mandarin argumental nominals are assumed to be DPs and the $\langle\mathrm{e}\rangle_{\mathrm{d}}$ in (54a) and (55a) is assigned range externally, not by movement. In this paper, Num-CL-N is labeled as \#P and CL-N as CIP despite their syntactic positions. 
38 Mandarin Bare Classifier-Nouns: Towards a Universal Structure for

(54) Argumental CL-N

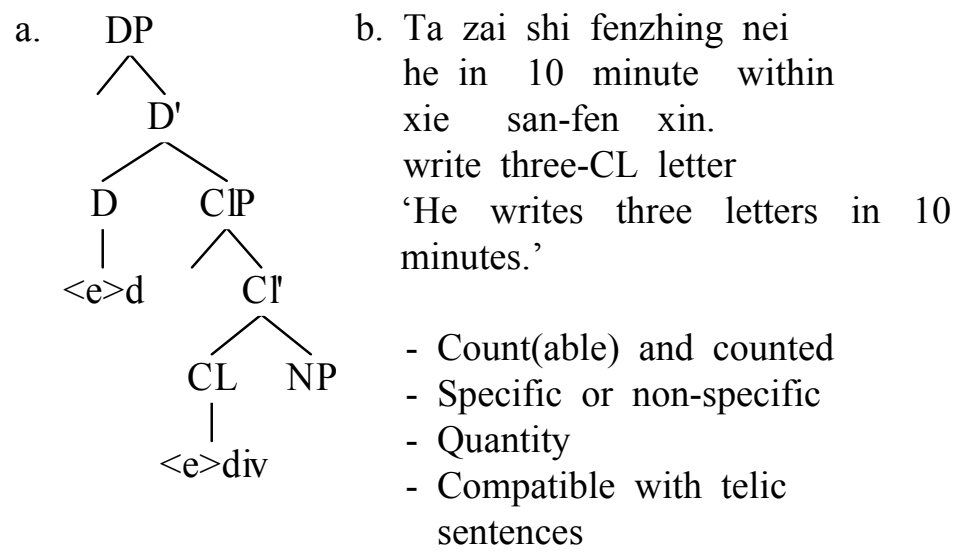

(55) Num-CL-N

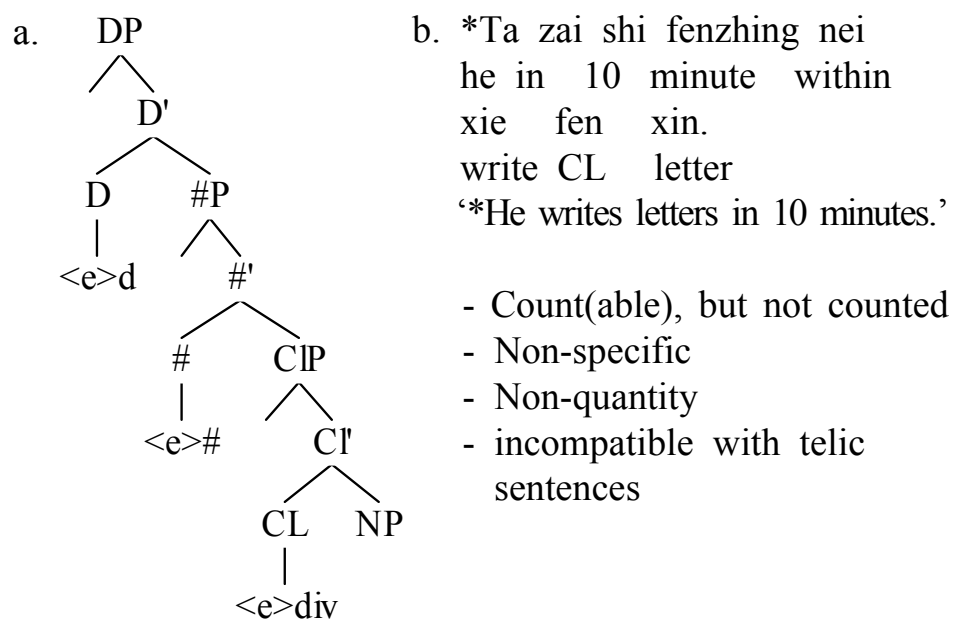




\section{Supporting Data from Num-CL-N and CL-N Distribution}

Adopting Borer's Exo-Skeletal approach, I hypothesize that Mandarin classifier morphology and English plural inflection are the same: both of them heading the ClP. Their major function is to make the nouns 'countable,' instead of to 'count' or quantize the nouns. The quantizing function is from the numerals or quantifiers (heading \#P), not from the classifiers or plural markers.

Mandarin CL-N and English $\mathrm{N}-s / e s$ are both ClPs carrying no quantity information. It is the numeral in Num-CL-Ns (\#Ps) that conveys quantity. Since whether carrying quantity information or not is the only difference between these two phrases, I predict that when the quantity information is needed in the discourse, Num-CL-Ns will be obligatory; on the contrary, when the quantity information is not crucial, CL-Ns will be preferred or obligatory. This prediction also accords with Grice's Conversational Maxim of Quantity (1975): make your contribution to the conversation as informative as necessary and do not make your contribution to the conversation more informative than necessary.

This prediction is consistent with what is found in Mandarin. Section 4.1 presents that in argument and non-argument positions where quantity information is crucial, only Num-CL-Ns are allowed. Section 4.2 shows that in some argument and non-argument positions, CL-Ns or bare Ns are preferred over Num-CL-Ns (in almost all cases, Num-CL-Ns are barred). Non-argument positions, in which only CL-Ns (or CL-Xs) are allowed, will be discussed in section 4.3.

\subsection{Obligatory Num-CL-N Cases}

When quantity is crucial information, I predict that \#Ps are required and ClPs are prohibited. This echoes with Lü's (1955: 87) 
40 Mandarin Bare Classifier-Nouns: Towards a Universal Structure for

observation that 'strong' $y i$ 'one' cannot be omitted. As illustrated below, when the target nominal appears in a negation sentence, or when it has a quantity expression, such as 'the same,' 'the whole,' or 'single,' the numeral is obligatory. Without the numeral, the sentence will be ungrammatical or infelicitous for the intended meaning. For all these cases, the nominals must cooperate with a quantifier, such as a numeral.

\subsubsection{Meaning: 'the Same' or 'Single Token'}

When referring to a single token of an object as in (56a-b), the number $y i$ 'one' must appear and bare CL-N cannot be used here. This is because the nominal phrase 'one chair' has wide scope over Zhangsan and Lisi, $y i$ 'one' must be present. Adding the adjective tong 'same' in sentence (56b) makes this scope effect even clearer - yi 'one' must appear to have scope over the subjects. On the contrary, when referring to two different chairs as in (56c), the CL-N can appear without any numerals. Note that here 'different chairs' does not have wide scope over Zhangsan and Lisi. The quantity of chairs may be irrelevant; thus CL-N is used.

$\begin{array}{lllll}\text { a. Zhangsan } & \text { he } & \text { Lisi } & \text { zuo } & \text { zai } \\ \text { Zhangsan } & \text { and } & \text { Lisi } & \text { sit } & \text { on } \\ \text { *(yi)-ba } & \text { yizi } & \text { shang. } & & \\ \text { one-CL } & \text { chair } & \text { top } & & \end{array}$

'Zhangsan and Lisi sit on one chair.'

$\begin{array}{lllll}\text { b. Zhangsan } & \text { he } & \text { Lisi } & \text { zuo } & \text { zai } \\ \text { Zhangsan } & \text { and } & \text { Lisi } & \text { sit } & \text { on } \\ \text { tong } & * \text { (yi)-ba yizi } & \text { shang. } & \\ \text { same } & \text { one-CL } & \text { chair } & \text { top } & \end{array}$

'Zhangsan and Lisi sit on the same chair.' (one token) 


$\begin{array}{lllll}\text { c. Zhangsan } & \text { he } & \text { Lisi } & \text { zuo } & \text { zai } \\ \text { Zhangsan } & \text { and } & \text { Lisi } & \text { sit } & \text { on } \\ \text { butong } & \text { ba } & \text { yizi } & \text { shang. } & \\ \text { different } & \text { CL } & \text { chair } & \text { top } & \end{array}$

'Zhangsan and Lisi sit on different chairs.'

\subsubsection{Meaning: 'the Whole'}

In a construction like (57), where $y i$ 'one' conveys 'the whole,' $y i$ must also be present. A quantity effect is observed for (56b) and (57): tong 'same' and dou 'all' both provide sense of quantity so these examples provide more evidence that CL-Ns are incompatible with quantity.

(57) *(Yi)-hu cha, $\quad$ *(yi)-pan dangao,
one-kettle tea, one-plate cake,
Zhangsan $\quad *$ (dou) chi-le
Zhangsan all
'Zhangsan finished up one kettle of tea and one plate
of cakes.'

\subsubsection{Meaning: 'Single'}

In sentences (56) and (57), the Num-CL-Ns are all in the argument position of a verb (57) or the argument position of a preposition (56). Sentence (58) is not an argument case but still the numeral $y i$ 'one' must appear because the quantity meaning is emphasized.

(58) Nimen bu qu, wo *(yi)-ge ren qu you-PL not go, I one-CL person go 'You (guys) don't want to go; I will go alone.' 
42 Mandarin Bare Classifier-Nouns: Towards a Universal Structure for

From examples (56) to (58), it seems self-explanatory that when the quantity is semantically prominent, the numeral must be present.

\subsection{CL-N Preferred Cases}

For the contexts that do not require quantity information, I predict that Mandarin CL-Ns (ClP) will be preferred, instead of Num-CL-Ns (\#P). In this section, constructions preferring CL-Ns are provided. Both argument and non-argument cases will be discussed: (i) imperative sentences, (ii) abstract nouns, (iii) copular sentences, (iv) predicative xiang 'as' and dang 'work as' constructions, and (v) wh-word constructions. All of these constructions prefer CL-Ns and sometimes these constructions even prohibit Num-CL-Ns overall depending on the intended meaning of the target nominals.

\subsubsection{Imperative Sentences}

The following imperative examples show that in both Mandarin and English, in a situation where the host encourages the guests to have some tea and cookies, only Mandarin bare Ns and CL-Ns can appear, but not Num-CL-Ns.

$$
\begin{aligned}
& \text { (59) a. He cha. } \\
& \text { drink tea } \\
& \text { 'Have (some) } \\
& \text { tea.' } \\
& \text { b. He bei cha. } \\
& \text { drink cup tea } \\
& \text { 'Have (some) tea.' }
\end{aligned}
$$


c. ${ }^{*} \mathrm{He} \quad$ yi/san-bei cha.

drink one/three-cup tea

'*Have one/three cup(s) of tea.'

(60) a. Chi binggan.

eat cookie

'Have (some) cookies.'

b. Chi kuai binggan.

eat CL cookie

'Have (some) cookies.'

c. *Chi yi/san-kuai binggan.

eat one/three-CL cookie

'*Have one/three piece(s) of cookies.'

Imperative sentences in (59) and (60) demonstrate that Mandarin 'drink tea' and 'drink cup tea' both mean 'have (some) tea' and there is no quantity involved. The guests can have as many cups of tea and as many cookies as they like. The same situation applies in English as shown in the translation. It is natural to say have a cookie, in which the host does not mean the guests can only have one cookie. However, it sounds odd and rude to say have one cookie. ${ }^{12}$ These examples also support the argument that CL-Ns contribute to no quantity readings.

\subsubsection{Abstract Nouns}

Most Mandarin abstract nouns, such as zisi 'selfishness,' bangzhu 'help,' and yongqi 'courage,' cannot appear with classifiers. For the abstract nouns that can compose with

12 A possible situation to say 'have one-CL cookie' in Mandarin is that a mom tells her child 'Have one-CL cookie. That's it. No more.' But it still sounds odd to say 'have one cookie' in English in the given context. 
44 Mandarin Bare Classifier-Nouns: Towards a Universal Structure for

classifiers, bare CL-Ns are preferred, while the acceptance of Num-CL-Ns and bare Ns is not consistent and seem to vary case by case. As demonstrated in (61a-c), the examples of abstract nouns here appear most naturally in the CL-N construction.

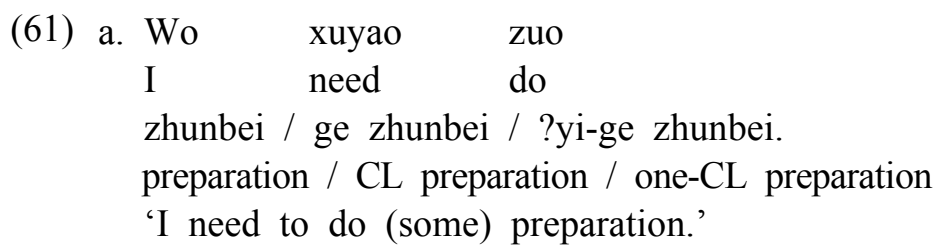

b. Jiaru ni fan ?zui / ge zui / ?yi-ge zui, if you commit crime / CL crime / one-CL crime, zhe beizi jiu wandan le. this life then finished SFP 'If you commit a crime, you are finished for this life.'

c. Ta zhiyao ti he only propose ?jianyi / ge jianyi / *yi ge jianyi, suggestion / CL suggestion / one-CL suggestion, dou meiyou ren gan fanbo ta. all nobody dare oppose he 'As long as he gives a suggestion, nobody dares to oppose him.'

\subsubsection{Copular Sentences}

The nominal predicates in copular sentences are non-referential; thus, no quantity information is needed and ClPs or bare Ns are expected. As shown in (62), Num-CL-Ns are either unacceptable (62a) or unnatural (62b) and CL-Ns are preferred for the intended 
meaning.

a. Zhangsan shi ?laoshi / ge laoshi / *yi-ge laoshi. Zhangsan be teacher/CL teacher/ one-CL teacher 'Zhangsan is a teacher.'

b. Paofu shi ?mao / zhi mao / ?yi-zhi mao. Puff be cat / CL-cat / one-CL-cat 'Puff is a cat.'

Yet the acceptability judgment for sentences in (62) seems suspicious in that if bare Ns and CL-Ns are similar in providing non-quantity homogeneous information, why bare Ns sound strange in these copular sentences, except in a list construction as in (63).

(63) Ta shi laoshi / ge laoshi / ?yi-ge laoshi, he be teacher / CL-teacher / one-CL teacher, wo shi yisheng / ge yisheng / ?yi-ge yisheng. I be doctor / CL doctor / one-CL doctor 'He is Teacher / a teacher. I am Doctor/a doctor.'

Recall that section 3 mentioned the difference between predicate bare $\mathrm{N}$ and CL-N in copular sentence, which is that post-copular bare $\mathrm{N}$ tends to have definite reading while CL-N offers non-referential reading expressing professions or roles of the subject, as shown in (51) and (52). This may account for the awkwardness for bare $\mathrm{N}$ to appear in (62) without a context.

Similarly, for English copular sentences, it is also the case that the ClP teachers (or \#/ClP a teacher) is allowed, not the bare NP teacher, as in (64), even though the $-s$ (or $a$ ) which heads the CIP does not add any meaning to the sentence. 
(64) a. John and Mary are teachers.

b. *John and Mary are teacher.

c. Bill is a teacher.

d. *Bill is teacher.

\subsubsection{Predicative 'as' Constructions}

More evidence for the hypothesis that non-argument or predicative positions not requiring quantity information will prefer CL-Ns can be found in predicative xiang 'as' and dang 'work as' constructions as shown in (65). It is interesting to note that as observed by Chen (2003), although the subject, fuzi 'father and son,' is plural, the nominal follows xiang 'as' does not stress any number information, and bare $\mathrm{N}$ or $\mathrm{CL}-\mathrm{N}$ are preferred. If a Num-CL-N, liang-ge faguoren 'two Frenchmen,' is used, the sentence is acceptable with a meaning of 'two certain Frenchmen.' The use of Num-CL-N is infelicitous for the intended meaning here. Munn \& Schmitt (2005) observe that Romance languages allow bare singulars in predicative as constructions while English does not. The Romance 'as' examples here are best translated as dang 'work as' in Mandarin, as shown in (65b, c, d, e). As example (65a), (65e) also illustrates that even though the word 'witness' is a predicate of 'we,' which is plural, 'witness' still prefers appearing in bare $\mathrm{N}$ or CL-N forms in this predicative position. It is unacceptable to use a numeral phrase here.

$\begin{array}{llll}\text { a. Tamen } & \text { fuzi } & \text { kanshangqu } & \text { xiang } \\ \text { they } & \text { father:son } & \text { look } & \text { as }\end{array}$
faguoren / ge faguoren / *yi(\#liang)-ge faguoren. Frenchman / CL Frenchman / one(two)-CL Frenchman 'The father and the son look like Frenchmen.' (adopted from Chen 2003: 1180 ex. (21)) ${ }^{13}$ 
b. Personne ne nous pourra

noone not us can.FUT

prendre comme témoin.

take as witness

'Nobody will be able to use us as witness.' (French)

c. Nadie podrá usarnos como testigo noone can.FUT use-us as witness

'Nobody will be able to use us as witness.' (Spanish)

d. Ninguém poderá nos usar como testemunha. nobody will-be-able us to-use as witness

'Nobody will be able to use us as witness.' $((65 b-d)=$ Munn $\&$ Schmitt 2005: 838 ex. (41)). (Brazilian Portuguese)

e. Meiyouren keyi yong women dang nobody can use we work as zhengren / ge zhengren / *yi(*liang)-ge zhengren. witness / CL witness / one(two)-CL witness 'Nobody can use us as witnesses.'

The predicative xiang 'as' and dang 'work as' constructions confirm that quantity is not required for interpretation in non-argument positions and the nominals without quantity structure, namely bare $\mathrm{N}$ and CL-N, are preferred.

\subsection{5. $W h$-words}

The sentence structures of the $w h$-words in (66) are consistent

13 Chen (2003) takes yi 'one' of (65) to be optional, but I found it unacceptable for the intended meaning. 
with what I found to be CL-N friendly environment. CL-who in (66a) and CL-what in (66b) are both predicative nominals in post-copular positions and CL-why in (66c) is an adverbial.

(66)

a. Zhangsan daodi shi ge shei ne?

Zhangsan after:all be CL who QP?

'Who is Zhangsan after all?'

b. $\mathrm{Na}$ shi ge shenme?

that be $\mathrm{CL}$ what?

'What is that?'

$\begin{array}{lllll}\text { c. Ni } & \text { yao } & \text { gen } & \text { wo } & \text { fenshou } \\ \text { you } & \text { want } & \text { with } & \text { me } & \text { break:up } \\ \text { ni } & \text { gaoshu } & \text { wo } & \text { ge } & \text { weishenme! } \\ \text { you } & \text { tell } & \text { me } & \text { CL } & \text { why } \\ \text { 'You want to break up with me! } & \text { You tell me why!' }\end{array}$

Note that when the classifier is dropped in (66), there seems not much meaning difference between CL-wh-words and bare wh-words.

The obligatory CL-N cases above affirm that whether or not quantity information is needed is the most crucial reason to allow or disallow bare CL-Ns to appear. Except not being able to contribute to the telic readings because of the lack of quantity, CL-Ns can appear in the argument positions of atelic sentences and in non-argument positions.

\subsection{An Obligatory CL-N Case:}

The current proposal predicts that in the cases where quantity information is not crucial, ClPs are preferred instead of 
Num-CL-Ns. Unsurprisingly, the most obvious places in which CL-Ns are expected to be preferred is in non-argument or predicative positions, where quantity is not required for interpretation (Munn \& Schmitt 2005: 829). In the previous section, CL-Ns preferred cases include argument and non-argument examples. This section discusses an obligatory CL-N case, which appears in a non-argument position, where both bare Ns and Num-CL-Ns are barred.

Some interesting cases of numeral-less classifiers found by Lü (1955) support the hypothesis that whenever 'counting' is not needed, ClPs, instead of \#Ps, are found. The difference between the following examples and the cases above is that these are obligatory numeral-less cases and the words following the classifiers are not usually assumed to be nominals - I will can them CL-X for now. These examples are adverbials as resultant states.

In (67), the target CL-Xs, such as ge tongkuai 'CL-to one's heart's content; satisfying,' are adverbials expressing a resultant state. Numerals, in these cases, must be absent and classifiers must be present so they are obligatory CL-X cases. Biq (2002) proposes a semantic/pragmatic analysis for what she calls CL-Complement, in which she argues that $\mathrm{V}$-ge-C expresses 'the attainment of an unusual resultant state' because they refuse further degree or extent modification such as hen 'very' in (68).

(67) a. Women jitian yao wan ge tongkuai. we today want play CL to one's heart's content 'We want to play to our heart's content today.'

b. Tiao jin yugang li pao ge shufu. jump into bathtub in bathe CL comfortable 'Jump into the bathtub to enjoy the utmost comfort (of bathing).' (=Biq 2002: 528 ex. (14)) 
(68) a. *Women jitian yao wan ge hen tongkuai. we today want play CL very to one's heart's content

b. *Tiao jin yugang li pao ge hen shufu. jump into bathtub in bathe $\mathrm{CL}$ very comfortable

She further notes that $\mathrm{C}$ is 'similar to the non-referential noun in that they both denote attributes and properties ...ge... is acting as a nominalizer, which promotes . . . the "nounhood" of C. This analysis echoes Borer's structural analysis that CL assigns nounhood to its complement. According to Borer's Exo-Skeletal approach, a listeme does not have syntactic categorical information in the lexicon. The English word book will be interpreted as noun if it is under a nominal functional structure, such as a ClP bound by plural $-s$. Therefore, it is syntactically logical to call this CL-X, CL-N.

In sum, section 4 discusses evidence supporting the argument that Mandarin CL-Ns are ClPs without quantity structure and Num-CL-Ns are \#Ps conveying quantity. Unlike previous analyses that usually focus on argumental CL-Ns, I have discussed CL-Ns in argument and non-argument positions in various constructions to attest that when the quantity information is needed in the discourse, Num-CL-Ns will be obligatory; in contrast, when the quantity information is not crucial, CL-Ns will be preferred or obligatory.

\section{Supporting Data from the Interaction of Aspect and (Num)-CL-N}

This section will examine the proposal in a larger construction, namely the verb phrases (VP). I will discuss the interaction 
between aspect, including lexical aspect and grammatical aspect, and the VP internal nominal structures. Section 4 provides supporting data to argue for a distinct distribution between Num-CL-N and CL-N, which is predicted by the current proposal that Num-CL-N (\#P) and CL-N (ClP) have different structures. This section will provide more evidence to support this distinction. Before that some background about aspect will be discussed. Aspect studies the event types as expressed by linguistic means. Aspect characterizes different ways of viewing the internal temporal constituency of a situation (Comrie 1976). Studies of aspect recognize two kinds of aspect: lexical aspect and grammatical aspect. Lexical aspect expresses the temporal properties of the predicate. Telic predicates, which involve logical end points, can be found in accomplishment predicates such as build a house, or achievement predicates such as fall or die. Stative predicates such as love or know, and activity predicates such as run or walk are called atelic predicates because they exclude logical end points. Grammatical aspect marks temporal viewpoints of an event by using linguistic devices, such as inflections. In English, for instance, have-past participle are in many cases used to indicate perfective aspect as in I have found my glasses. Present tense and present progressive specify imperfective aspect as in he walks or he is walking.

Mandarin has no markers for tense. Instead, the speakers use adverbial time phrases, such as yesterday or next year, to indicate time; however, time phrases are not required in grammatical sentences. Since there is no tense morphology in Mandarin, aspect makers become the focus when studying grammatical aspect. It is not conclusive how many aspect markers there are in Mandarin, yet only three traditionally-accepted aspect makers will be discussed, namely the perfective marker -le, the imperfective marker zai, and the experiential marker $-q u o .14$ The goal of this

14 The durative marker $-z$ he will not be discussed since -zhe usually appears with 
section is to provide more evidence to support the proposal that the different structure of Num-CL-N and CL-N can account for their different distribution. It will not thoroughly discuss the interaction among each type of nominals, lexical aspect, and grammatical aspect. Only the interaction of a specific type of predicates with a specific marker will be discussed. For example, achievement predicates will not be discussed with the progressive zai because they simply do not co-occur in Mandarin.

\subsection{Different Distribution for [Num-CL-N/Bare $N]$ and [CL-N]}

This section provides data with telic and atelic constructions that will differentiate the distribution of Num-CL-N and definite bare $\mathrm{N}$ (both have \#P projection) from CL-N (which has no \#P projection).

\subsubsection{Telic Verbs with/without the Perfective Marker}

One of the characteristics of lexical aspect is its compositionality. An activity verb like write is atelic, while write a book is an accomplishment predicate, which is telic. The VP internal argument, a book, provides an end point to the writing activity; thus write a book is telic. When discussing lexical aspect, both the verb itself and the VP internal argument have to be taken into consideration. That is perhaps why when Sybesma (1992) argues for telicity and specificity in V Num-CL-N sentences, he

stative verbs and intransitive activity verbs, which mostly appear without an internal argument. The focus of this paper, CL-N, generally appears in postverbal positions; hence I will not discuss the interaction between the durative marker -zhe and nominal types. For discussion about other possible aspect markers or aspectual constructions in Mandarin, please see Li \& Thompson 1981, Egerod 1994, and Li \& Bowerman 1998. 
is careful to confine his argument for 'predicates that are telic for reasons independent of the object.' Since Cheng \& Sybesma (1999), who observed the distinction between Num-CL-N and CL-N, use examples with a resultative such as 'eat up' and 'drink up,' to make it easier to compare across different lexical aspect and aspect markers, I will mainly use chi 'eat' and a resultative compound chi-wan (eat-finish) 'eat up' as examples for atelic and telic constructions respectively. Sybesma (1992: 176-178, cited in Cheng \& Sybesma 1999) argues that for sentences with a verb 'that is telic for reasons independent of the object' a strong reading is forced upon the object: a bare noun 'cookie' is interpreted as definite, an indefinite NP 'one/two cookie(s)' as specific, as shown below. Telic sentences (69) and (70) show that only Num-CL-Ns with a specific reading and bare Ns with a definite reading as in (a) cases are acceptable, whereas bare CL-Ns as in (b) cases are not acceptable.

a. Wo chi-wan yi-kuai I eat-finish one-CL

binggan / liang-kuai binggan / binggan, cookie / two-CL cookie / cookie, jiu qu xi wan. then go wash dish '(After) I eat up a cookie / two cookies / the cookie, I will wash the dishes.'

$\begin{array}{llll}\text { b. *Wo } & \text { chi-wan } & \text { kuai } & \text { binggan, } \\ \text { I } & \text { eat-finish } & \text { CL } & \text { cookie, } \\ \text { jiu } & \text { qu } & \text { xi } & \text { wan. } \\ \text { then } & \text { go } & \text { wash } & \text { dish } \\ \text { '*(After) } & \text { I eat up piece cookie, I will wash the dishes.' }\end{array}$ 
(70)

a. Wo chi-wan-le

I eat-finish-LE

yi-kuai binggan / liang-kuai binggan / binggan.

one-CL cookie / two-CL cookie / cookie

'I ate up a cookie / two cookies / the cookie.'

b. *Wo chi-wan-le kuai binggan.

I eat-finish-LE CL cookie

'*I ate up piece cookie.'

Note that bare nouns are acceptable in (69a) and (70a) with a definite reading. According to Borer, definite nominals obtain their quantity information anaphorically from the context; thus \#P must project. In other words, only nominals that have \#P projection can occur as the object of the telic predicate chi-wan 'eat up.' Also note that no matter how fast the sentence is pronounced, sentences (69b) and (70b) are still ungrammatical because of the CL-N. There is no phonological reason why $y i$ 'one' could not be suppressed in (69b) and (70b); therefore, phonological reduction analysis claiming $y i-\mathrm{CL}-\mathrm{N}$ to become CL-N cannot account for the data here.

Cheng \& Sybesma are probably the first ones to discover the need to distinguish $y i$-CL-N from CL-N. Their argument, however, is presented solely with examples with resultative verb compound, such as chi-wan 'eat up' or he-wan 'drink up' plus the perfective marker -le. Thus, a question raises whether -le plays a role in the prohibition of CL-N. Examples (69) and (70) show that no matter whether a perfective marker -le is present or not this distinct behavior of Num-CL-N / definite bare $\mathrm{N}$ and CL-N is true. The perfective marker -le does not seem to have anything to do with the prohibition of CL-N.

Examples like (69b) and (70b) support Cheng \& Sybesma's (1999) argument that CL-N phrases in Mandarin must be 
nonspecific indefinites, which account for their incompatibility with telic verbs. However, based on the current proposal, another way to account for the data is that nominals with quantity information, Num-CL-Ns and definite bare Ns, can co-occur with telic verbs either with (70) or without (69) the perfective marker -le, while non-quantity CL-Ns cannot.

\subsubsection{Atelic Verbs with/without the Progressive Marker}

Cheng \& Sybesma discover the need to distinguish yi-CL-N from CL-N based on the sentences with verbs 'that are telic for reasons independent of the object' and the previous section confirms the need to distinguish Num-CL-N from CL-N for telic verbs without any affixes, chi-wan 'eat up,' and for telic verbs with the perfective -le, chi-wan-le 'eat up-LE.' This observation seems to suggest that this distinction should not appear in examples with verbs that are atelic for reasons independent of the object. This prediction is supported in (71) with an atelic verb, chi 'eat,' which allow all types of nominals to appear.

(71) Wo chi yi-ke pingguo / pingguo / ke pingguo I eat one-CL apple / apple / CL apple dang wucan. as lunch

'I eat an apple / (the) apple(s) / an apple for lunch.'

When the progressive marker zai is present, I expect the $z a i$-atelic verb sequence to be able to take all kinds of nominals since the zai-'eat' combination provides atelic aspectual reading for the sentence. However, as shown in (72), the Num-CL-N / bare $\mathrm{N}$ and CL-N distribution difference is attained and the prediction is not correct. 
(72) a. Wo zai-chi yi-kuai dangao. I ZAI-eat one-CL cake 'I am eating a cake.'

b. Wo zai-chi dangao. I ZAI-eat cake 'I am eating the cake/cakes.'

c. *Wo zai-chi kuai dangao. I ZAI-eat CL cake '*I am eating piece cake.'

The unacceptability of (72c) should not be taken as evidence to go against the prediction that $\mathrm{ClP}$ can appear in atelic sentences, but not in telic sentences. There is some peculiarity of the progressive zai sentence that makes CL-N unacceptable in this construction. I will present some observation below and leave the issue open for further research.

Something interesting about the zai construction is that $y i-\mathrm{CL}-\mathrm{N}$ and bare $\mathrm{N}$ are acceptable, but Num-CL-N with other numerals and CL-Ns are not (no matter how hard we push the interpretation), as in (73).

(73) a. Zhangsan zai-xie xin.

Zhangsan ZAI-write letter

'Zhangsan is writing letters / the letter.'

b. Zhangsan zai-xie yi-fen xin / *san fen xin. Zhangsan ZAI-write one-CL letter/three-CL letter 'Zhangsan is writing one letter / three letters.'

c. *Zhangsan zai-xie fen xin. Zhangsan ZAI-write CL letter 'Zhangsan is writing CL letter.' 
In (73a), the bare $\mathrm{N}$ xin 'letter' can have an indefinite reading and zai-xie xin 'ZAI-write letter' will mean 'engaging in letter-writing activities' and the bare $\mathrm{N}$ will be kind-referring here. The bare $\mathrm{N}$ can also be interpreted as a definite to mean 'write the letter.' For (73b), since the progressive maker provides the durative viewpoint, 'writing three letters' will be infelicitous or will get funny interpretation. Therefore, numerals except 'one' are barred in this construction. The unacceptable CL-N examples in (72c) and (73c) contradict Cheng \& Sybesma and Borer's claim that CL-N always gets singular interpretation. If CL-N always gets singular interpretation, it should be allowed in the zai construction. Zai provides a progressive viewpoint to an event and the event is viewed as, for example, ongoing 'cake-eating' or 'letter-writing' activities at the reference time of the sentence. The ongoing activity can only be expressed in Mandarin by using a kind-referring bare $\mathrm{N}$, a definite bare $\mathrm{N}$, or a Num-CL-N carrying $y i$ 'one' but not other numerals.

\subsubsection{Atelic and Telic Verbs with the Experiential Marker}

The aspectual interpretation of a sentence is compositional. We have to take into consideration both the lexical aspect (the (a)telicity of the VP) and the grammatical aspect (the aspect markers in Mandarin). An atelic verb chi 'eat' occurring with the experiential -guo will result in telic sentences. CL-Ns cannot occur in telic sentences; therefore, the Num-CL-N / bare N and CL-N distinction is also observed as in (74).

$\begin{array}{llll}\text { a. Wo chi-guo lanmei } & \text { binggan. } \\ \text { I } & \text { eat-GUO blueberry } & \text { cookie }\end{array}$

'I had the blueberry cookies.' (context: during an afternoon tea break)

'I have the experience of eating blueberry cookies.' 
$\begin{array}{llll}\text { b. Wo chi-guo yi-kuai lanmei } & \text { binggan. } \\ \text { I } & \text { eat-GUO one-CL blueberry } & \text { cookie } \\ \text { 'I ate one blueberry cookie.' } & \end{array}$

$\begin{array}{llll}\text { c. *Wo chi-guo kuai lanmei } & \text { binggan. } \\ \text { I } & \text { eat-GUO } & \text { CL blueberry cookie } \\ \text { 'I ate a blueberry cookie.' } & \end{array}$

Due to the function of the experiential marker -guo, which expresses past experience, bare $\mathrm{N}$ in (74a) can have two interpretations: the definite reading and the 'indefinite past' reading as called in Chao (1968) and Li \& Thompson (1981). According to Li \& Thompson (1981) and Smith (1997), -guo can express that an event has taken place or been experienced at least once. Take (74a) for example, one of the interpretations introduced by $-g u o$ is that the event of my eating blueberry cookies has happened at least once. In this case, the bare $\mathrm{N}$ which is said to have 'indefinite past' reading can also be claimed to have kind-referring reading. Yet a question arises: why bare $\mathrm{N}$ with indefinite reading (74a) can appear, but CL-N (74c), which may also provide indefinite reading, cannot. In accordance with the current proposal, CL-N is not allowed in the -guo construction due to its ClP structure, which lacks the \#P projection. Unlike CL-N, Mandarin bare $\mathrm{N}$ can be interpreted as definite; therefore, bare $\mathrm{N}$ may always have \#P projected in order to be readily assigned range to produce definite readings. (The \#P of definite bare $\mathrm{N}$ is bound anaphorically by the context.) In brief, a -guo sentence is telic and asks for quantity expression, which can be provided by nominals with \#P projections.

As discussed earlier, the resultative telic constructions, such as chi-wan 'eat up,' never co-occur with CL-N. A telic verb appearing with -guo also distinguish Num-CL-N / bare $\mathrm{N}$ from CL-N as illustrated in (75). 'Eat up-guo' may co-occur with bare Ns (75a) and Num-CL-Ns (75b), but not with CL-Ns (75c). 
$\begin{array}{llll}\text { (75) a. Lisi } & \text { hen } & \text { nengchi, ta } & \text { yi-ge } \\ \text { Lisi } & \text { very } & \text { can:eat, he one-CL } \\ \text { ren } & \text { chi-wan-guo } & \text { jiehun dangao. } \\ \text { person } & \text { eat-up-GUO } & \text { marriage } & \text { cake }\end{array}$

'Lisi can eat a lot. He had the experience of eating up wedding cakes by himself.'

b. Ta chi-wan-guo yi-ge jiehun dangao.

He eat-up-GUO one-CL marriage cake

'He had the experience of eating up a wedding cake.'

c. *Ta chi-wan-guo ge jiehun dangao.

he eat-up-GUO CL marriage cake

'He had the experience of eating up a wedding cake.'

To sum up, Cheng \& Sybesma are careful to confine their argument by stating that CL-Ns cannot co-occur with verbs 'that are telic for reasons independent of the object.' Since this Num-CL-N and CL-N distributional distinction is not the focus of their research, they do not dig deep into this issue. The current study further ascertains that ndt only telic verbs 'that are telic for reasons independent of the object' will prohibit the appearance of CL-Ns. The distribution of CL-Ns interacts not only with verbs, but with the combination of various lexical aspect and aspect markers. For example, some telic constructions (such as 'eat up,' 'eat up-le,' 'eat-up-guo,' 'eat-guo') and atelic constructions (such as zai-'eat') all argue for the distinction between Num-CL-N and CL-N.

Now clearly it is not accurate to argue for $y i$-CL-N to CL-N reduction (section 2.1) or the existence of a covert numeral for CL-N (section 2.2). yi-CL-N cannot always be suppressed to CL-N and $y i-C L-N$ (or Num-CL-N) has a broader distribution than CL-N. CL-N is prohibited in the places where \#P is required. 
60 Mandarin Bare Classifier-Nouns: Towards a Universal Structure for

\subsection{Sameness: Constructions Allowing [Num-CL-N], [Bare N], and [CL-N]}

The previous section presents data arguing for the distinction between Num-CL-N and CL-N, which consist with the proposal that they have different syntactic structures. This section will examine the constructions that allow all three types of nominals, Num-CL-N, bare N, and CL-N, to see whether these constructions will conflict with the proposal or they can be accounted for in a way in accordance with the proposal.

\subsubsection{Atelic Verbs with the Perfective Marker}

The aspectual reading of a sentence results from the combination of the verb and the aspect markers. A sentence which has an atelic verb pao 'run' and the perfective marker -le will be telic because the perfective marker -le can delimit the event, as shown in (76). The best English translation for (76) will be 'he ran away' or 'he escaped.' It is as if -le draws a boundary to the atelic event of running. Although it is arguable whether this boundary is drawn at the beginning of the activity to mean 'escaped' or at the end of the activity to express the result 'away,' there is no problem to claim that -le marks the boundary of activities.

(76) \#ta pao-le

$\mathrm{He}$ run-LE

'He escaped.' 'He ran away.'

We have seen that CL-N is not allowed in telic constructions because of its lack of quantity information. A sentence which has an atelic verb chi 'eat' and the perfective marker -le will be telic; thus CL-N should not be permitted in this type of sentences. Yet 
the examples in (77) contradict the prediction in that all three types of nominal structures are allowed.

$$
\begin{aligned}
& \text { a. Wo chi-le binggan. } \\
& \text { I eat-LE cookie } \\
& \text { 'I ate the cookie(s).' }
\end{aligned}
$$

b. Wo chi-le yi-kuai binggan / san-kuai binggan. I eat-LE one-CL cookie / three-CL cookie 'I ate a cookie / three cookies.' (implying completion: full consumption of the cookie(s))

c. Wo chi-le kuai binggan. I eat-LE CL cookie 'I ate a cookie / *cookies.' (implying completion: full consumption of one cookie)

The bare $\mathrm{N}$ in (77a) can only be interpreted as definite, for which DP and \#P will project but not ClP since there is no range assigner for the $\mathrm{ClP}$ head. As discussed earlier, the \#P of the definite nominals obtains its quantity interpretation anaphorically from the context. Sentence $(77 b)$ is only felicitous if the objects referred in the sentence, one cookie or three cookies, are fully consumed. Therefore, I argue that the default interpretation for $\mathrm{V}$-le is a completed event and consequently -le will force CL-N to get a singular interpretation to convey a completed event. The singular reading of the CL-N in $(77 \mathrm{c})$ is provided by the perfective marker -le, not the nominal CL-N itself. Remember that CL-N is a ClP which does not have \#P projection and carries no quantity information; however, CL projection is a counter, which means the $\mathrm{CL}$ in $(77 \mathrm{c})$ makes the ClP 'ready to be counted' and a completed event denoted by the perfective marker -le will give CL-N a singular reading. This 'CL-N gets singular interpretation' case does not necessarily contradict the proposal that $\mathrm{ClP}$ has no 
62 Mandarin Bare Classifier-Nouns: Towards a Universal Structure for

quantity reading because it is the perfective marker -le that provides boundedness to the event and gives rise to the singular interpretation of CL-N.

\subsubsection{Modal and Serial Verbs}

Modal construction expresses modality or future events. Sentences with a modal xiang 'want' and an atelic verb chi 'eat' are predicted to allow Num-CL-N, bare N, and CL-N, while sentences with a modal and a telic verb chi-wan 'eat up' should prohibit CL-N because CL-N does not co-occur with telicity. As predicted, all three types of nominal structures are allowed in the modal-atelic verb construction as shown in (78). Sentence (78a) which has a \#P seems to emphasize the quantity that the subject intends to consume. The bare nominal in (78b) can be interpreted as kind-referring or definite depends on the context. The CL-N in (78c) does not express any quantity and an indefinite reading will obtain. This is similar to the imperative sentences discussed before: the kind-referring (78b) and indefinite (78c) do not provide boundedness to the event. When a guest tells the host that he is going to have 'one banana' (78a), it would be odd if he gets two bananas right after his utterance. Nevertheless, it is felicitous if the guest has more than one banana if he utters $(78 b, c)$.
a. Wo xiang chi yi/san-gen xiangjiao. I want eat one/three-CL banana
'I want to eat a banana / three bananas.'

b. Wo xiang chi xiangjiao. I want eat banana

'I want to eat bananas / the banana.'

c. Wo xiang chi gen xiangjiao. I want eat CL banana 
'I want to eat bananas.'

When a modal appears with a telic verb chi-wan 'eat up,' as predicted, \#P must project and only definite bare $\mathrm{N}$ and Num-CL-N are allowed and CL-N is prohibited, as in (79).

$\begin{array}{llll}\text { a. Wo } & \text { xiang } & \text { chi-wan } & \text { yi-gen } \\ \text { I } & \text { want } & \text { eat-finish } & \text { one-CL } \\ \text { xiangjiao } & \text { jiu } & \text { hao } & \text { le. } \\ \text { banana } & \text { just } & \text { okay } & \text { SFP }\end{array}$

'I just want to finish a banana. That's all.'

$\begin{array}{clll}\text { b. Wo xiang } & \text { chi-wan } & \text { xiangjiao. } \\ \text { I } & \text { want } & \text { eat-finish } & \text { banana }\end{array}$

'I want to finish the banana.'

$\begin{array}{lllll}\text { c. *Wo xiang } & \text { chi-wan } & \text { gen } & \text { xiangjiao. } \\ \text { I } & \text { want } & \text { eat-finish } & \text { CL } & \text { banana } \\ \text { 'I want to finish bananas.' } & \end{array}$

One easy way to account for the distributional difference in (78c) and (79c) is that CL-N simply does not co-occur with a telic verb, such as chi-wan 'eat up.' However, some people may wonder what the difference is between 'eat a banana' and 'eat up a banana' in Mandarin since they seem to have similar meaning in English. Without any aspect markers, 'eat a banana' and 'eat up a banana' expect the same result - the banana is gone at the end of the event. Nevertheless, 'eat a banana' is an accomplishment and 'eat up a banana' is an achievement predicate in Mandarin. ${ }^{15}$ Just like other achievement verbs, such as die or win, Mandarin

15 According to Chang's (2013), Mandarin resultatives are achievements, which cannot take the progressive marker zai. 
resultatives focus on the result instead of the process. The focus of 'eat a banana' is the eating process, while the focus of 'eat up a banana' is the result of wan 'finished, up.' An interesting phenomenon in Mandarin is that the termination of an accomplishment event can be cancelled as shown in (80a), while the completion of an achievement event cannot be cancelled as in (80b) (Smith 1997, Soh \& Kuo 2005).

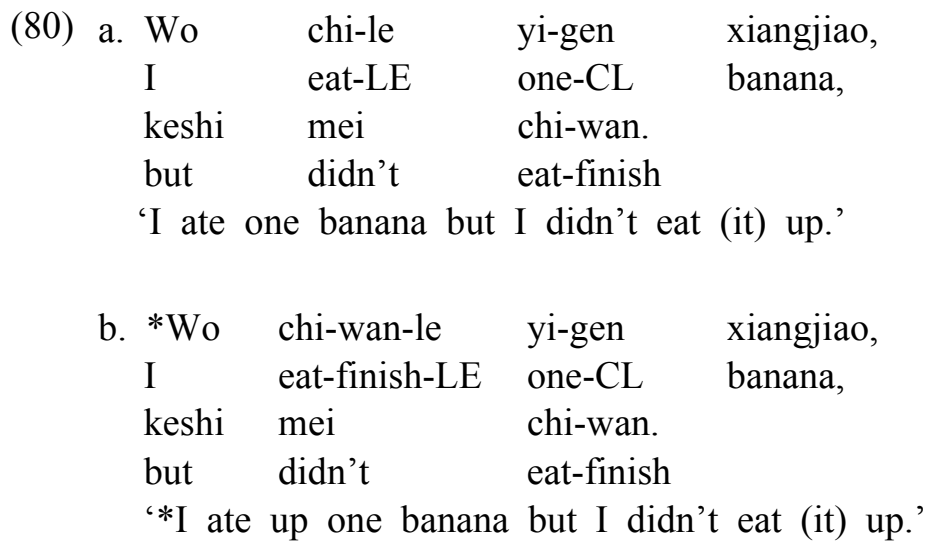

In short, chi-wan 'eat up' cannot appear with CL-N because it emphasizes the result of a completed event which requires a quantity nominal. CL-N is not bounded and cannot contribute to this achievement event.

Another special construction in Mandarin that is worth mentioning is the serial verb construction, which contains two or more verbs. The individual verbs in this construction are related to each other in a temporal way and have a consecutive relation. For instance, the serial verb construction $q u$ chi 'go eat' expresses an event including at least two subevents, i.e., 'go' and 'eat.' My prediction is sustained in this serial verb construction - a serial atelic verb construction (81) will allow Num-CL-N, bare $\mathrm{N}$ and CL-N, while a serial telic verb construction (82) will allow 
Num-CL-N, definite bare N, but prohibit CL-N.

(81) a. Wo qu xie gongke.

I go write homework

'I'll go and write homework.'

b. Wo qu xie yi-fen gongke.

I go write one-CL homework

'I'll go and write a homework assignment.'

c. Wo qu xie fen gongke.

I go write CL homework

'I'll go and write a homework assignment.'

(82) a. Wo qu xie-wan gongke.

I go write-finish homework

'I'll go and write up the homework.'

b. Wo qu xie-wan yi-fen gongke.

I go write-finish one-CL homework

'I'll go and write up a homework assignment.'

c. *Wo qu xie-wan fen gongke.

I go write-finish CL homework

As in the modal construction, CL-N cannot appear in the serial verb construction when a telic verb is part of the serial verb construction and requires its accusative argument to contain quantity information and to be bounded.

\subsection{Summary}

The interaction among lexical aspect (using chi 'eat' and chi-wan 'eat up' as examples for atelic and telic aspect), grammatical aspect 
markers, and different types of nominals is summarized in Table 1. Num-CL-N and bare $\mathrm{N}$ can occur in all the constructions discussed in this section but CL-N has some distributional restrictions. CL-N is totally prohibited in telic sentences, which are exemplified by using a resultative compound verb, chi-wan 'eat up.' CL-N is also forbidden in the atelic verb plus the experiential -guo construction, which results in a telic sentence.

Table 1. Interaction among Lexical Aspect, Aspect Markers, and Types of Nominals

\begin{tabular}{|c|c|c|c|c|c|c|}
\hline \multicolumn{2}{|c|}{ Mandarin: } & $\mathrm{N}$ & Num-CL N & CL-N & $\begin{array}{l}\text { Prediction } \\
\text { for CL-N }\end{array}$ & Section \\
\hline \multirow{2}{*}{ Bare $\mathrm{V}$} & eat up & $\sqrt{ }$ & $\sqrt{ }$ & $*$ & $*$ & 5.1 .1 \\
\hline & eat & $\sqrt{ }$ & $\sqrt{ }$ & $\sqrt{ }$ & $\sqrt{ }$ & 5.1 .2 \\
\hline \multirow{2}{*}{$\begin{array}{l}\text { Perfective } \\
-L E\end{array}$} & eat up- $L E$ & $\sqrt{ }$ & $\sqrt{ }$ & * & * & 5.1 .1 \\
\hline & eat- $L E$ & $\sqrt{ }$ & $\sqrt{ }$ & $\sqrt{ }$ & $*$ & 5.2 .1 \\
\hline \multirow{2}{*}{$\begin{array}{l}\text { Experiential } \\
\text {-GUO }\end{array}$} & eat up-GUO & $\sqrt{ }$ & $\sqrt{ }$ & $*$ & $*$ & \multirow{2}{*}{5.1 .3} \\
\hline & eat-GUO & $\sqrt{ }$ & $\sqrt{ }$ & $*$ & $*$ & \\
\hline \multirow{2}{*}{$\begin{array}{l}\text { Progressive } \\
Z A I\end{array}$} & $* Z A I$-eat up & & & & & \\
\hline & $Z A I$-eat & $\sqrt{ }$ & $\sqrt{ }$ & $*$ & $\sqrt{ }$ & 5.1 .2 \\
\hline \multirow{2}{*}{ Modal } & want-eat up & $\sqrt{ }$ & $\sqrt{ }$ & $*$ & $*$ & \multirow{4}{*}{5.2 .2} \\
\hline & want-eat & $\sqrt{ }$ & $\sqrt{ }$ & $\sqrt{ }$ & $\sqrt{ }$ & \\
\hline \multirow{2}{*}{ Serial verbs } & go-eat up & $\sqrt{ }$ & $\sqrt{ }$ & $*$ & $*$ & \\
\hline & go-eat & $\sqrt{ }$ & $\sqrt{ }$ & $\sqrt{ }$ & $\sqrt{ }$ & \\
\hline
\end{tabular}

The gray area indicates a contradiction between the prediction and the fact.

The atelic 'eat' plus the perfective -le construction, which provides telic reading to the sentence, is predicted to forbid the appearance of CL-N. The fact which contradicts my prediction has been accounted for in section 5.2.1 by arguing that -le provides 
boundedness to the sentence and gives CL-N a singular interpretation. The progressive zai plus atelic 'eat' sequence offering atelic viewpoint is predicted to allow CL-N, but this prediction turns out to be incorrect. One possibility is that, as discussed in 5.1.2, the progressive zai construction cannot allow numerals other than 'one' in the accusative argument position that is why 'he is drinking one cup of coffee' is good while 'he is drinking two cups of coffee' is impossible in Mandarin. In other words, zai requires a 'one' reading, which CL-N cannot offer, and there is no other element in the sentence that may provide the 'one' reading. Therefore, CL-N is barred in this construction.

\section{Conclusions}

This paper has shown that the phonological reduction, covert numeral, and semantic specificity accounts for Mandarin CL-Ns can explain some of the data, but the syntactic approach proposed here, based on Borer's Exo-Skeletal theory, can account for more variety of constructions, including the argumental CL-Ns and the non-argumental cases, such as the predicates in copular sentences, adverbials, and so on, which have been neglected in previous research. Besides, the previous accounts were proposed mainly for Mandarin data, including Borer's proposal for a fused \#/ClP specifically for Mandarin classifiers, while this account argues for a cross-linguistic structure, namely a ClP for both English books and Mandarin ben shu 'CL book.'

This proposal supports Borer's argument that classifier morphology and plural inflection are in fact the different realization of the same thing. Their major function is to make the nouns 'countable,' instead of to 'count' the nouns. The quantification function is from the numerals or quantifiers, not from the classifiers or plural markers. This study also gives 
evidence that it is not necessary to argue for different structures for English plural morphology and Mandarin classifiers as did by Borer. English plural morphology and Mandarin classifiers both head the CIP. In consequence, this paper supports the view that examining the nominal structure across languages is possible, which simplifies the effort to analyze language-specific data by proposing language-specific arguments.

Given the CL-N issue and different approaches to the problem, we need a strategy to evaluate possible explanations. This study examines different constructions to argue for an analysis that has more explanatory power than previous studies. I used as standpoints the quantity/non-quantity of the nominals, the positions of the nominals: arguments or non-arguments, and the interaction between the telicity of the predicates and the internal argumental nominals to test the hypothesis among different distributions of CL-Ns in Mandarin in hope that this work will shed some light in the cross-linguistic consistency and comparison of nominal structures.

\section{References}

Biq, Y-O. 2002. Classifier and Construction: The Interaction of Grammatical Categories and Cognitive Strategies. Language and Linguistics 3, 521-542.

Borer, H. 2005a. In Name Only. Oxford: Oxford University Press. . 2005b. The Normal Course of Events. Oxford: Oxford University Press.

Chang, H-H. 2013. The Aspect Marker -Le in Early Child

Mandarin. Journal of Universal Language 14.1, 7-54.

Chao, Y-R. 1968. A Grammar of Spoken Chinese. Berkeley: University of California Press.

Chen, P. 2003. Indefinite Determiner Introducing Definite 
Referent: Special Use of 'Yi 'One' + Classifier' in Chinese. Lingua 113, 1169-1184.

Cheng, L. 2005. On Every Type of Quantificational Expression in Chinese. Paper presented at The Workshop on QP structure, nominalization, and the role of DP. Saarbrücken.

Cheng, L. \& R. Sybesma. 1999. Bare and Not-So-Bare Nouns and the Structure of NP. Linguistic Inquiry 30, 509-542. . 2005. Classifiers in Four Varieties of Chinese. In G. Cinque \& R. Kayne (eds.), The Oxford Handbook of Comparative Syntax 259-292. Oxford: Oxford University Press.

Comrie, B. 1976. Aspect: An Introduction to the Study of Verbal Aspect and Related Problems. Cambridge: Cambridge University Press.

Dowty, D. 1979. Word Meaning and Montague Grammar. Dordrecht: Kluwer Academic Publishers.

Egerod, S. 1994. Aspect in Chinese. In C. Bache, H. Basbøll, \& C-E. Lindberg (eds.), Tense, Aspect, and Action: Empirical and Theoretical Contributions to Language Typology 279-309. New York: Mouton de Gruyter.

Gao, Q. 1994. Chinese NP Structure. Linguistics 32, 475-510. Grice, H. (1975) 1989. Logic and Conversation. Studies in the Way of Words 22-40. Cambridge, MA: Harvard University Press.

$\mathrm{Hu}, \mathrm{F}$. 1958. Shu ci he liang ci [Numeral phrases and measure phrases]. Shanghai: Xinzhishi Chubanshe.

Li, C. \& S. Thompson. 1981. Mandarin Chinese: A Functional Reference Grammar. Los Angeles, CA: University of California Press.

Li, P. \& M. Bowerman. 1998. The Acquisition of Lexical and Grammatical Aspect in Chinese. First Language 18.3, 311-350.

Li, Y-H. 1998. Argument Determiner Phrases and Number Phrases. Linguistic Inquiry 29, 693-702. 
70 Mandarin Bare Classifier-Nouns: Towards a Universal Structure for

Li, W. 2000a. Numeral-Classifiers as a Grounding in Mandarin Chinese. Journal of Chinese Linguistics 28, 337-368. . 2000b. The Pragmatic Function of Numeral-Classifiers in Mandarin Chinese. Journal of Pragmatics 32, 1113-1133. Liu, F-H. 2003. Definite NPs and Telicity in Chinese. Snippets 7, 13-15.

Lü, S. (1945) 1955. Ge zhi de yingyong fanwei fulun danwei ci qian $y i$ zhi de tuoluo [The application range of 'ge' and the omission of 'yi' before the classifiers]. Hanyu yufa lunwen ji [The paper collection of Chinese grammar] 69-94. Beijing: Kexue chubanshe.

. 1980. Xiandai Hanyu babai ci [800 Phrases of Modern Chinese]. Hong Kong: Shangwu yingshuguang.

Munn, A. \& C. Schmitt. 2005. Number and Indefinites. Lingua $115,821-855$.

Peyraube, A. 1998. On the History of Classifiers in Archaic and Medieval Chinese. In B. T'sou, A. Peyraube, \& L. Xu (eds.), Studia Lingusitica Serica 131-145. Hong Kong: Hong Kong City University.

Smith, C. 1997. The Parameter of Aspect ( $2^{\text {nd }}$ edition). Dordrecht: Kluwer Academic Publishers.

Soh, H. \& J. Kuo. 2005. Perfective Aspect and Accomplishment Situations in Mandarin Chinese. In H. Verkuyl, H. de Swart, \& A. van Hout (eds.), Perspectives on Aspect 199-216. Dordrecht: Springer.

Sybesma, R. 1992. Causatives and Accomplishments: The Case of Chinese $b a$. Ph.D. Dissertation. HIL/Leiden University.

Tang, C-C. 1990. A Note on the DP Analysis of the Chinese Noun Phrase. Linguistics 28, 337-354.

Yang, R. 2001. Common Nouns, Classifiers, and Quantification in Chinese. Ph.D. Dissertation. Rutgers, The State University of New Jersey. 